\title{
An in vitro model for the cultivation of polymicrobial biofilms under continuous-flow conditions [version 1; peer review: 2
}

\section{approved]}

\author{
Thomas James O'Brien (iD1, Marwa Mohsen Hassan (iD2, Freya Harrison2, \\ Martin Welch ${ }^{1}$ \\ ${ }^{1}$ Department of Biochemistry, University of Cambridge, Cambridge, CB2 1QR, UK \\ ${ }^{2}$ School of Life Sciences, University of Warwick, Coventry, CV4 7AL, UK
}

V1 First published: 13 Aug 2021, 10:801
https://doi.org/10.12688/f1000research.55140.1

Latest published: 13 Aug 2021, 10:801

https://doi.org/10.12688/f1000research.55140.1

\begin{abstract}
The airways of people with cystic fibrosis (CF) are often chronically colonised with a diverse array of bacterial and fungal species. However, little is known about the relative partitioning of species between the planktonic and biofilm modes of growth in the airways. Existing in vivo and in vitro models of CF airway infection are ill-suited for the long-term recapitulation of mixed microbial communities. Here we describe a simple, in vitro continuous-flow model for the cultivation of polymicrobial biofilms and planktonic cultures on different substrata. Our data provide evidence for inter-species antagonism and synergism in biofilm ecology. We further show that the type of substratum on which the biofilms grow has a profound influence on their species composition. This happens without any major alteration in the composition of the surrounding steady-state planktonic community. Our experimentally-tractable model enables the systematic study of planktonic and biofilm communities under conditions that are nutritionally reminiscent of the CF airway microenvironment, something not possible using any existing in vivo models of CF airway infection.
\end{abstract}

\section{Keywords}

Cystic fibrosis (CF), polymicrobial, biofilms, in vitro models, 3Rs

\section{NC \\ $3 R^{s}$}

This article is included in the NC3Rs gateway.

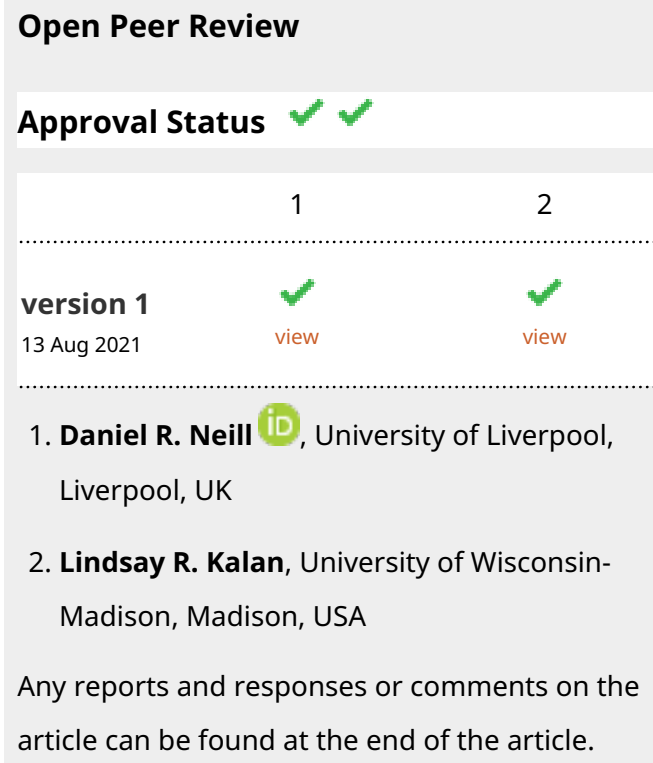

2. Lindsay R. Kalan, University of Wisconsin-

Madison, Madison, USA

Any reports and responses or comments on the article can be found at the end of the article. 
Corresponding author: Martin Welch (mw240@cam.ac.uk)

Author roles: O'Brien TJ: Conceptualization, Data Curation, Formal Analysis, Funding Acquisition, Investigation, Methodology, Validation, Visualization, Writing - Original Draft Preparation, Writing - Review \& Editing; Hassan MM: Investigation, Methodology, Resources, Writing - Review \& Editing; Harrison F: Methodology, Resources, Writing - Review \& Editing; Welch M: Conceptualization, Funding Acquisition, Project Administration, Supervision, Writing - Review \& Editing

Competing interests: No competing interests were disclosed.

Grant information: This work was supported by a studentship (NC/P001564/1) from the NC3Rs to support TO'B, and consumables support from a UK Cystic Fibrosis Trust Venture and Innovation award and from the British Lung Foundation. $\mathrm{FH}$ and $\mathrm{MH}$ were supported by a grant from the MRC (ref. MR/R001898/1).

The funders had no role in study design, data collection and analysis, decision to publish, or preparation of the manuscript.

Copyright: ( 2021 O'Brien TJ et al. This is an open access article distributed under the terms of the Creative Commons Attribution License, which permits unrestricted use, distribution, and reproduction in any medium, provided the original work is properly cited.

How to cite this article: O'Brien TJ, Hassan MM, Harrison F and Welch M. An in vitro model for the cultivation of polymicrobial biofilms under continuous-flow conditions [version 1; peer review: 2 approved] F1000Research 2021, 10:801

https://doi.org/10.12688/f1000research.55140.1

First published: 13 Aug 2021, 10:801 https://doi.org/10.12688/f1000research.55140.1 
Research highlights

\section{Scientific benefits}

- Allows for direct comparison of biofilm and planktonic microbial lifestyles.

- Allows for longitudinal and real-time analysis of interspecies interactions among polymicrobial biofilms.

\section{Rs benefits}

- Reduces the need for vertebrate infection models when studying microbe-microbe interactions in the context of cystic fibrosis.

\section{Practical benefits}

- Inexpensive and simple to operate.

- Chemically defined culture conditions, allows for the reproducible study of subtle interspecies interactions.

- Experimentally tuneable, allows for different species combinations or disease states to be studied.

\section{Current applications}

- Studying changes in ecology of polymicrobial biofilm formation during co-culture on different solid substrata.

\section{Potential applications}

- Studying changes in gene expression and behaviour of polymicrobial biofilms comprising of different species combinations.

- Studying response of polymicrobial biofilms and planktonic communities against treatment with antimicrobials for the development and validation of polymicrobial biofilm dispersal/treatment regimens.

\section{Introduction}

Cystic fibrosis (CF) is a life-limiting genetic disorder estimated to affect 70,000 people worldwide (Cystic Fibrosis Foundation). Although a systemic multi-organ disease, the most striking manifestation of CF is chronic obstruction of the airways via an overproduction of viscous, nutrient-rich airway secretions. These secretions block the airways and predispose people with CF to life-long microbial infection. These infections are frequently polymicrobial and comprise both bacterial and fungal species (Ahmed et al., 2019; Boutin et al., 2015; Carmody et al., 2015; Hogan et al., 2016; Jorth et al., 2019; Mahboubi et al., 2016; Rogers et al., 2010; Sibley and Surette, 2011; Zhao et al., 2012). CF airway infections contribute towards a decline in pulmonary function and it is estimated that $\sim 90 \%$ of persons with CF succumb to respiratory failure as a direct result of microbial infection (Chmiel and Davis, 2003; Elborn, 2016; Lubamba et al., 2012; Lyczak et al., 2002; Rajan and Saiman, 2002; Sibley et al., 2006).

Recent years have seen increasing recognition that inter-species interactions between the airway microbiota may play a role in modulating the behaviour, virulence, and even the response to therapeutic intervention (Antonic et al., 2013; Armbruster et al., 2016; Baldan et al., 2014; Barnabie and Whiteley, 2015; Beaume et al., 2015; Briaud et al., 2019; Dalton et al., 2011; Diggle et al., 2007; Elias and Banin, 2012; Hotterbeekx et al., 2017; Hibbing et al., 2010; Korgaonkar et al., 2013; Mastropaolo et al., 2005; O'Brien and Fothergill, 2017; Peters et al., 2012; Weimer et al., 2010). Moreover, co-culturing bacterial species in vitro and in vivo has been shown to lead to significant alterations in the expression of core essential genes (Ibberson et al., 2017; Ibberson and Whiteley, 2020). One particularly important unaddressed question relates to the impact of co-habiting species on the biology of Pseudomonas aeruginosa (PA). PA is a common inhabitant of the CF airways, and a model organism for the study of biofilms. However, the paucity of experimentally tractable in vivo or in vitro models of CF infection has severely hampered the in-depth and longitudinal study of such polymicrobial communities (O'Brien and Welch, 2019b).

It has been estimated that at least $60 \%$ of bacterial infections in the western world involve the formation of biofilms (Fux et al., 2005) and CF is no exception. One crucial feature of microbial biofilms is their increased ability to bypass effective immune clearance and resist antimicrobial action. Indeed, some bacterial biofilms are up to $1000 \times$ more resistant to antimicrobial intervention compared with their planktonic cell counterparts (Parsek, 2003). The formation of biofilm-like aggregates in the $\mathrm{CF}$ airways is often cited as a reason why therapeutic strategies aimed at eradicating keystone $\mathrm{CF}$ pathogens such as PA fail (Bjarnsholt et al., 2009; Döring et al., 2011; Elias and Banin, 2012; Folkesson et al., 2012; Leekha et al., 2011; Lopes et al., 2012; Lopes et al., 2014; Mowat et al., 2011). However, our understanding of how 
inter-species interactions alter biofilm physiology remains limited. This is important because agonistic and antagonistic interactions between species almost certainly confer a significant selection pressure, thereby driving adaptive divergence in members of the polymicrobial community (Markussen et al., 2014; Schick and Kassen, 2018; Winstanley et al., 2016).

There are three key vertebrate models of CF available to researchers: the CF mouse, the CF ferret and the CF pig (reviewed recently by O'Brien and Welch, 2019b). Although the porcine airways share a remarkable degree of genetic and structural homology with human airways (Judge et al., 2014; Rogers et al., 2008), the cost and technical/ethical complexity of using porcine models ensures they are rarely used in research. CF ferrets are also rarely used, since they develop severe airway infections soon after birth and subsequently succumb to respiratory failure (Hoffman and Hajjar, 2018; Sun et al., 2010), although this situation may change as in utero administration of cystic fibrosis transmembrane conductance regulator (CFTR) modulators can rescue this severe phenotype (Sun et al., 2019). By contrast, the CF mouse is widely used, with $>14$ different distinct models available (Guilbault et al., 2007). However, and despite the widespread availability of these murine CF models, their usefulness for studying chronic airway infection is limited. CF mice do not develop spontaneous airway infections (Bayes et al., 2016; Cash et al., 1979; van Heeckeren et al., 2006), and artificiallyinduced infections of the airways are rapidly cleared if the inoculated microbial species are not immobilised using agar/ agarose/alginate beads (Chattoraj et al., 2010; Hoffmann et al., 2005; Moser et al., 2009; Munder et al., 2011). As with $\mathrm{CF}$ ferrets, this prevents the long-term study of polymicrobial communities and interspecies interactions.

Due to inherent limitations in the way in which the data is reported, the exact number of animals used for research into CF airway infections is difficult to ascertain. Yet a systematic review of the literature up to 2015 has found 12,304 publications discussing the use of CF animal models. Of those that are primary research articles (799 publications), 636 report the use of $\mathrm{CF}$ mice, rats, pigs, ferrets or zebrafish (with the remaining publications not reporting the use of any genetic CF models) (Leenaars et al., 2020). Given that this literature review only accounts for publications up to 2015 , and given the recent surge of interest into understanding the polymicrobial communities associated with $\mathrm{CF}$ airway infections, the number of $\mathrm{CF}$ animals used in research will have certainly increased over the last six years. Despite the importance of biofilms in CF pathology, and their well-known link with increased patient mortality rates, there is currently no suitable in vivo model for the study of polymicrobial biofilm communities in the context of CF. Furthermore, none of the aforementioned 636 studies report the use of CF models to study polymicrobial biofilm communities. Practical limitations when sampling the airway microbiota in infected animal models mean that the animals must be sacrificed and their lungs excised before histopathological examination. Not only are there significant ethical implications associated with these approaches, but the longitudinal/long-term study of microbial populations becomes impractical. More recently, ex vivo models of CF have redressed some of these issues, enabling the study of microbial biofilm lifestyles reminiscent of those observed in situ (Harrington et al., 2020; Sweeney et al., 2021). However, owing to the intense competition observed among microbial species, existing ex vivo models do not yet permit the study of more than one microbial species at a time. This is a significant experimental limitation when studying long-term polymicrobial infection scenarios such as CF. Hence, the in vitro model we describe here provides a novel tool for the study of mixedspecies biofilms that is not currently possible using existing in vivo $\mathrm{CF}$ models.

The primary limitations of in vitro infection models, compared with in vivo models, is a lack of host cells and a functional immune system (which may contribute towards clearing microbial infections in situ). However, it should be noted that impaired immune clearance of microbes in an inherent feature of $\mathrm{CF}$, which somewhat mitigates the lack of a functional immune system in in vitro models (Cohen and Prince, 2012; Bonfield and Chmiel, 2017). Although in vitro models do not capture all aspects of human disease pathophysiology, they do provide an ideal tool for studying interspecies interactions between microbes (O'Brien and Welch, 2019b). Emerging evidence suggests that chemical, not spatiotemporal, factors have the greatest impact on driving changes in microbial lifestyles (Lopes et al., 2017; Quinn et al., 2015). Hence, the defined and experimentally-perturbable nature of in vitro models are an attractive option for studying microbial behaviour in a reductive manner. Furthermore, the development of artificial sputum medium (ASM), closely mimicking the nutritional composition of CF airway secretions, provides an unparalleled opportunity for the study of polymicrobial populations under conditions that chemically recapitulate the CF microenvironment (Haley et al., 2012; Sousa et al., 2018; Sriramulu et al., 2005; Turner et al., 2015; Frapwell et al., 2018). However, simply mixing CF airwayassociated species together in ASM and hoping for the best is not a recipe for success. This is because the co-cultures display compositional instability, and the initially diverse community rapidly become dominated by just one or a few species. To remedy this, we developed an in vitro model of CF (O'Brien and Welch, 2019a). Importantly, our model permits planktonic microbial communities of three distinctly different species associated with CF airway infections (PA, Staphylococcus aureus (SA) and Candida albicans (CA)) to be maintained, indefinitely, as a stable steady-state community. In this report we build upon our existing model and describe a simple, yet versatile, method of culturing polymicrobial biofilms on different solid substrata. 
The model described in this work permits the simultaneous cultivation of steady-state planktonic and biofilm communities, allowing for direct comparisons to be made between these two modes of microbial growth. In principle, any combination of microbial species associated with CF airway infections could be cultured using the setup. As such, not only does our system reduce the need for in vivo $\mathrm{CF}$ infection models for studying microbe-microbe interactions; it enables the real-time, longitudinal study of polymicrobial communities in an experimentally reproducible, controlled setup. It has not escaped our notice that this model system is also well-suited for the road-testing of interventions aimed at preventing the formation of biofilms in chronic $\mathrm{CF}$ airway infections.

\section{Methods}

Methods for the model development

Microbial strains

All microbial strains used in this work are shown in Table 1. Strains were routinely cultured in lysogeny broth (LB) (Formedium) on a $40 \mathrm{~cm}$ diameter rotating drum with mild aeration $\left(0.5\right.$ rotations per second) at $37^{\circ} \mathrm{C}$ overnight.

Continuous-flow culture vessel and biofilm container

Artificial sputum medium (ASM) was used as the main growth medium for all experiments and was prepared as previously described (O'Brien and Welch, 2019a). The continuous-flow culture system has also been previously described (O'Brien and Welch, 2019a). Both are described in more detail in the protocol below. Briefly, the culture vessel consists of a $100 \mathrm{~mL}$ Duran flask, fitted with an assembled 4-port HPLC GL80 screw cap (Duran). A 24-channel IPC ISM934C standard-speed digital peristaltic pump (Ismatec) was used to deliver sterile ASM from a media reservoir at a defined flowrate $(Q)$ through $1.5 \mathrm{~mm}$ bore sterilin silicon tubing (Fisher Scientific) to the culture vessel. A different channel of the same pump was used to remove waste culture into a discard jar at the same flowrate (Figure 1). Biofilms

Table 1. Microbial strains used in this study.

\begin{tabular}{|l|l|l|}
\hline Strain & Description & Reference \\
\hline PAO1 & $\begin{array}{l}\text { Pseudomonas aeruginosa, spontaneous chloramphenicol-resistant } \\
\text { derivative. Used worldwide as a laboratory reference strain (isolated } \\
\text { Melbourne, 1954) }\end{array}$ & (Holloway, 1955) \\
\hline $\begin{array}{l}\text { ATCC } \\
25923\end{array}$ & $\begin{array}{l}\text { Staphylococcus aureus Rosenbach (ATCC }{ }^{\circledR} \text { 25923D-5 } \\
\text { clinical isolate. methicillin sensitive } \\
\text { (isolated Seattle, 1945) }\end{array}$ & (Treangen et al., 2014) \\
\hline SC5314 & $\begin{array}{l}\text { Candida albicans, clinical isolate commonly used as a wild-type laboratory } \\
\text { reference strain (isolated New York, 1980's) }\end{array}$ & (Gillum et al., 1984) \\
\hline
\end{tabular}

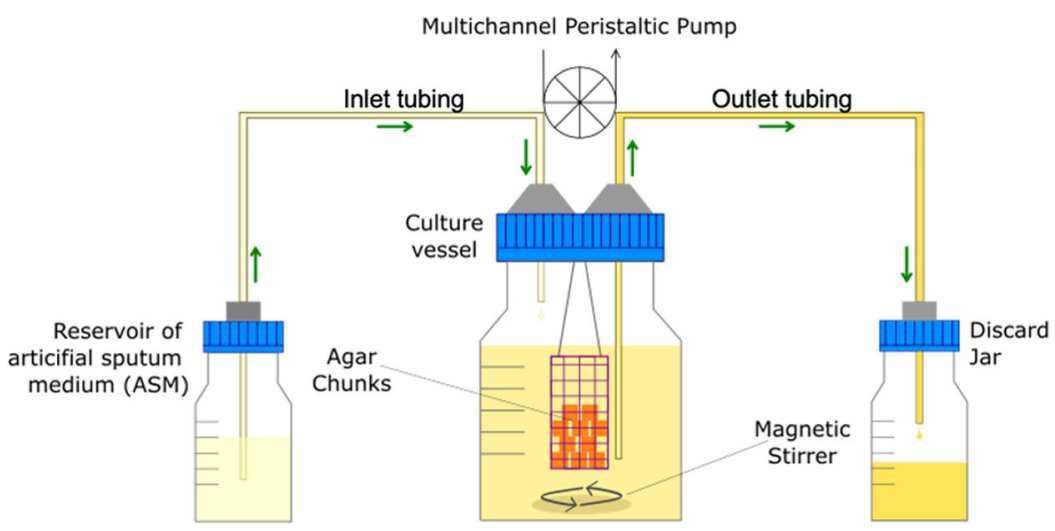

Figure 1. Schematic diagram of the continuous-flow culture vessel containing biofilm container. The main culture vessel (centre) is a $100 \mathrm{~mL}$ Duran bottle fitted with a 4-port HPLC GL80 screwcap lid, containing four sealable inlet/outlet ports from which the biofilm container is suspended. A multichannel peristaltic pump delivers fresh media (ASM) into the culture vessel from a reservoir (left), and also removes waste culture into a discard jar (right) at the same rate of flow $(Q)$. Arrows show the direction of media flow. The culture vessel and media reservoirs are incubated at $37^{\circ} \mathrm{C}$ and the contents are kept homogenous through gentle stirring (100 rpm). The value of $Q$ depends on the microbial species being cultured within the vessel. 
were allowed to develop in the continuous-flow culture vessel on two types of solid substratum; agar chunks and ex vivo porcine lung tissue (EVPL) sections, which have been previously reported to closely mimic the airway surface environment (Harrison et al., 2014; Harrison and Diggle, 2016; Sweeney et al., 2021; Harrington et al., 2020). These substrata were suspended in bespoke cylindrical biofilm containers ( $25 \mathrm{~mm}$ diameter $\times 35 \mathrm{~mm}$ length) constructed from stainless steel wire gauze (Fisher Scientific) (Figure 2A,B). Containers were then suspended in the culture vessel hanging from a piece of silicon tubing threaded through two of the unused HPLC ports (Figure 2C). The entire culture system was maintained at $37^{\circ} \mathrm{C}$ and the liquid contents of the vessel were kept homogenous by stirring (100 rpm) using a round magnetic stir bar (length $20 \mathrm{~mm}$, diameter $8 \mathrm{~mm}$ ).

Preparation of biofilm substratum

Agar plates (2.5\% w/v agar in milliQ water) were poured to a depth of $5 \mathrm{~mm}$. Using a sterile number 21 scalpel and a set of sterile $12.7 \mathrm{~cm}$ curved forceps, cubes of approximately $5 \mathrm{~mm}$ x $5 \mathrm{~mm}$ were cut from the plate and transferred into the sterile biofilm container. Biofilm work using EVPL sections was performed in collaboration with Dr Freya Harrison at the

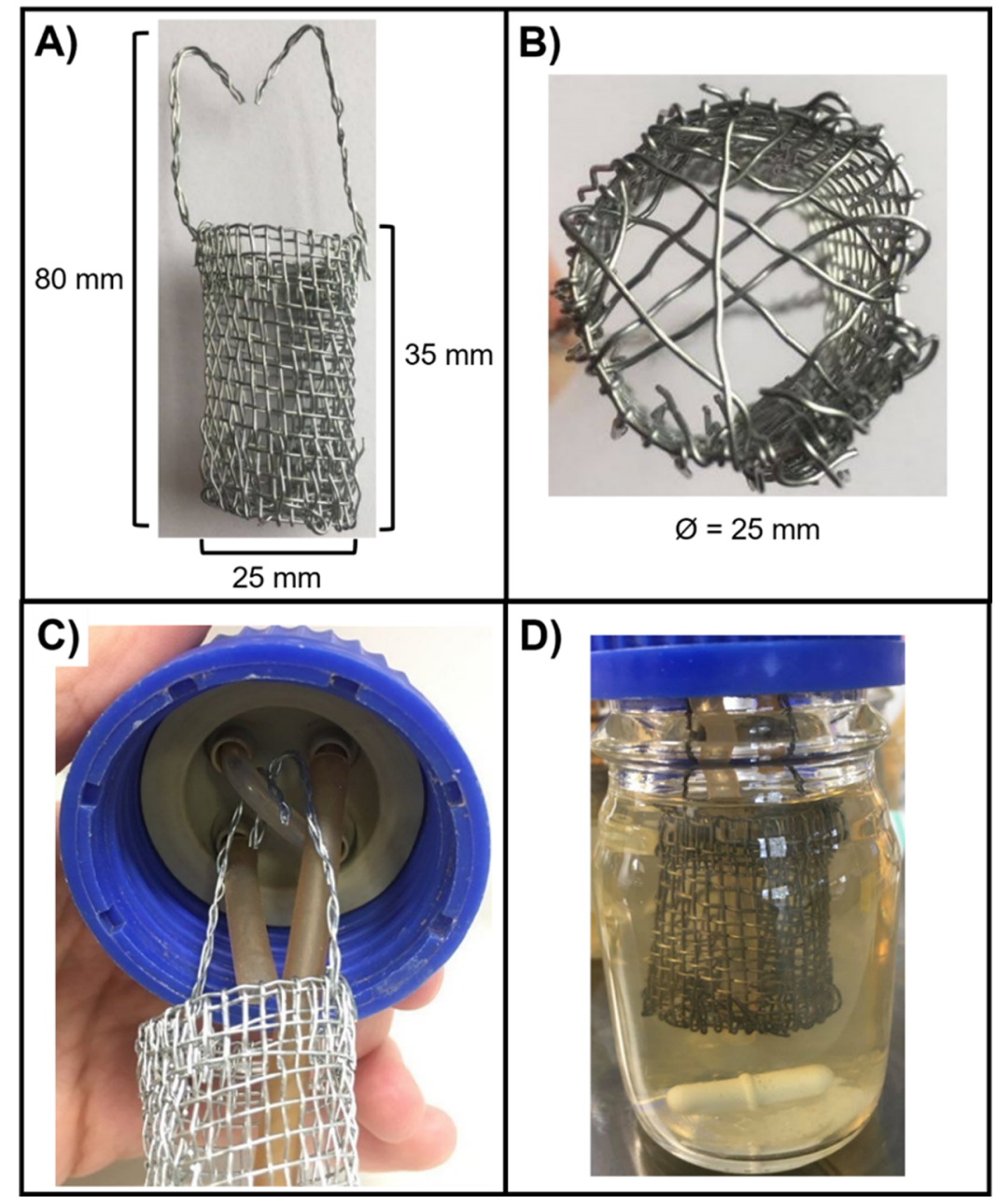

Figure 2. Container for culturing biofilms under continuous-flow conditions. The biofilm container constructed from stainless steel gauze for this study. Biofilm containers consisted of a cylinder, $35 \mathrm{~mm}$ in length and $25 \mathrm{~mm}$ in diameter (Ø), connected to two stainless steel arms (45 mm in length), which suspend the container from the HPLC screw-port lid. (A) Side view of the container with dimensions. (B) Bottom view of the container. Single strands of stainless-steel wire were threaded across the bottom of the container to form a mesh and prevent the biofilm substratum from falling through. A small gap $(\sim 3 \mathrm{~mm} \varnothing)$ was also included for the outlet tube to be threaded through to allow the removal of culture media during incubation. (C) View of the 4-port HPLC screw cap lid. The left port is the media inlet, the right port is the media outlet and the two remaining ports are threaded with a single piece of rubber tubing ( $1.5 \mathrm{~mm}$ bore) to hold the arms of the mesh container. (D) The biofilm container in situ in the assembled setup. Note that the container is completely submerged in the growth medium but is separated from the magnetic stir bar to prevent interference with the continual stirring of the culture vessel. 


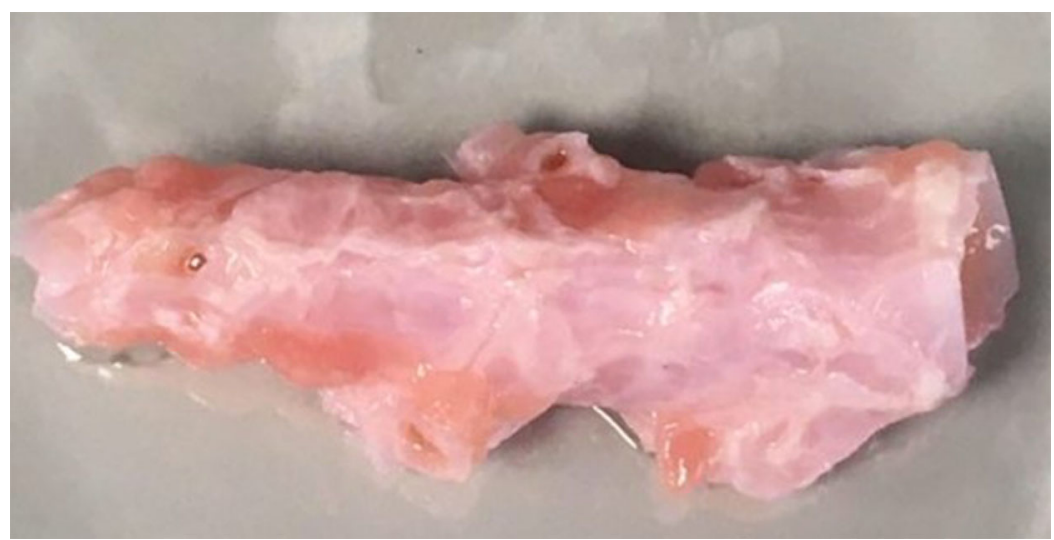

Figure 3. Ex vivo porcine bronchiole. A single bronchiole excised from porcine lung tissue after cleaning and a single wash in DMEM/RPMI solution. All alveolar and vascular tissue was removed using a razor blade and dissection scissors. After cleaning, bronchiole tissue was cut into $5 \mathrm{~mm} \times 5 \mathrm{~mm}$ squares for use as solid substratum to promote biofilm growth.

University of Warwick, using previously described methods (Harrison and Diggle, 2016). Briefly, fresh pig lungs were collected from the butcher (John Taylor, Earlsdon, UK) and processed within the hour. To remove surface contaminants, a $25 \mathrm{~cm}$ palette knife was heated until red-hot using a Bunsen burner and briefly tapped $(<1 \mathrm{~s})$ on the area to be dissected. Working with aseptic technique, a sterile razor blade was used to excise the bronchiole and remove all alveolar tissue; a cleaned bronchiole can be seen in Figure 3. Bronchioles were washed in Dulbecco's Modified Eagle Medium (DMEM)/ Roswell Park Memorial Institute 1640 Medium (RPMI) solution (50:50 ratio, $40 \mathrm{~mL}$ ) and cut into $5 \mathrm{~mm}$ wide strips with sterile dissection scissors. The strips were washed in DMEM/RPMI and cut into $5 \mathrm{~mm} \times 5 \mathrm{~mm}$ squares. EVPL sections were washed again in DMEM/RPMI, then transferred to a petri dish containing $40 \mathrm{~mL}$ ASM and irradiated in UV lightbox for $5 \mathrm{~min}$ before being aseptically transferred to the biofilm container [Full dissection methods for the production of EVPL tissue sections are also demonstrated in an open access video protocol (Harrington et al., 2021)].

Culture vessel inoculation and incubation

Overnight cultures of the microbial strains (grown in LB as described above) were washed three times in phosphatebuffered saline (PBS) prior to inoculating the culture vessel. Pre-warmed ASM $\left(37^{\circ} \mathrm{C}, 100 \mathrm{~mL}\right)$ was added to the culture vessel and inoculated with the required combination of microbial species. The optical density (at $600 \mathrm{~nm} ; \mathrm{OD}_{600 \mathrm{~nm}}$ ) of the washed microbial cultures was then measured using a spectrophotometer (Eppendorf BioSpectrometer kinetic) and each species was introduced into the culture vessel to achieve a starting $\mathrm{OD}_{600 \mathrm{~nm}}$ of 0.05 . The culture vessel was then incubated for three hours with stirring prior to starting the flow of medium $\left(Q=145 \mu \mathrm{L} \mathrm{min}{ }^{-1}\right)$.

Sample collection

For characterisation of biofilm populations, pieces of substratum were aseptically removed at the indicated times and transferred to $500 \mu \mathrm{L}$ PBS in 24-well microtiter plates. Loosely attached planktonic cells were removed from the substratum by briefly swirling the plates. The substratum was then transferred to a second well in the same plate and washed once more. Finally, after a third wash, the samples were transferred into $2 \mathrm{~mL}$ bead beating tubes containing $1 \mathrm{~mL}$ PBS and eighteen metal beads ( $2.38 \mathrm{~mm}$ diameter, Qiagen). The tubes were them agitated in a FastPrep-24 5G benchtop homogeniser (MP Biomedicals) for $40{\mathrm{~s} \mathrm{at} 4 \mathrm{~m} \mathrm{~s}^{-1} \text { to liberate the cells. CFU mL }}^{-1}$ counts were performed as described below. Three separate substratum pieces were sampled at each time point (yielding three biological replicates per timepoint, per independent biological experiment). Samples of the planktonic culture $(1 \mathrm{~mL})$ were removed directly from the culture vessel using a sterile serological pipette. Independent biological experiments were then performed over separate independent weeks using fresh microbial cultures and pieces of biofilm substratum without any deviation from the methods detailed in this article.

$\mathrm{CFU} \mathrm{mL}^{-1}$ enumeration

Colony forming units (CFU) were determined using the single plate-serial dilution spotting method, as described previously (Thomas et al., 2015). Briefly, 10-fold serial dilutions of the microbial cultures were made in sterile PBS and $20 \mu \mathrm{L}$ of each dilution was spotted (approximately $2 \mu \mathrm{L}$ per drop) onto the appropriate selective agar. Three types of 


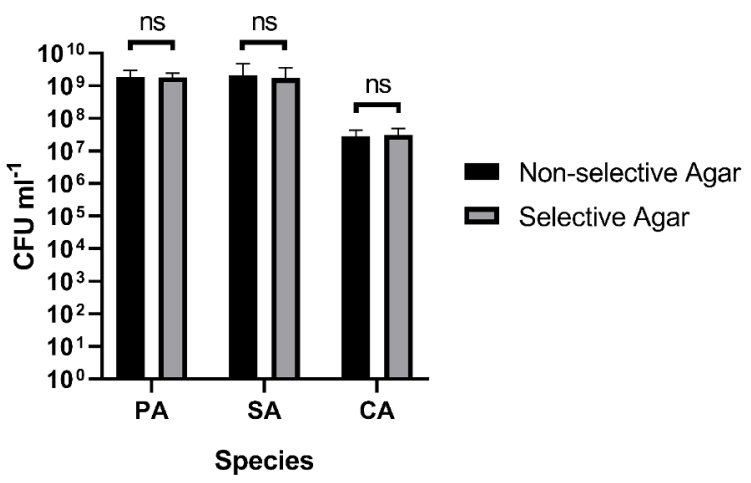

Figure 4. Comparison of cell titres on selective and non-selective agar. The figure shows the viable cell counts (expressed as CFU mL ${ }^{-1}$ ) of overnight single-species cultures of $P$. aeruginosa PAO1 (PA), S. aureus 25923 (SA) and C. albicans SC5314 (CA) plated on non-selective agar media (black bars) and selective agar media (grey bars). Data represent the mean \pm standard deviation from two technical replicates collected from three independent biological experiments. $P>0.05$ is considered as not significantly different (ns).

selective agar were used to enumerate microbial cell counts of the different species present in a single sample: PA was isolated using Pseudomonas isolation agar (PIA, Oxoid), SA was isolated using mannitol salt agar (MSA, Oxoid) and CA was isolated onto BiGGY agar (Oxoid). When enumerating cell counts from the polymicrobial cultures, the agar plates used to isolate PA and SA were further supplemented with $5 \mu \mathrm{g} \mathrm{mL}^{-1}$ itraconazole to inhibit the growth of CA. The different selective media only permit the growth of a single microbial species of interest and inhibit the growth of the other species present. This enables $\mathrm{CFU} \mathrm{mL} \mathrm{mL}^{-1}$ counts for each species in the polymicrobial culture to be determined with confidence [note that when studying other co-cultures containing other combinations of microbial species, different types of selective media may be required for the selective enumeration of other species]. All plates were incubated at $37^{\circ} \mathrm{C}$. PIA and MSA plates were incubated overnight $(16 \mathrm{~h})$ and BiGGY agar plates were incubated for $24 \mathrm{~h}$. Three independent samples of biofilm substratum from the same culture vessel were removed per timepoint (corresponding to three biological replicates). For each biological replicate, three independent serial dilutions were made and plated out for CFU enumeration (constituting three technical replicates per each piece of substratum sampled), non-blinded CFU $\mathrm{mL}^{-1}$ counts were then recorded as the average of the technical replicates. Two independent samples of culture supernatant were removed from each culture vessel per timepoint (corresponding to two technical replicates) to enumerate planktonic CFU $\mathrm{mL}^{-1}$ counts of each species.

We tested whether there was any significant difference in cell counts determined on non-selective $v s$ selective agar, and there was not (Figure 4 and underlying data (O'Brien et al., 2021)). To test this, we performed serial dilutions of overnight microbial cultures (routinely grown in LB as described above) and plated the same dilution series onto LB-agar (nonselective) and the appropriate selective agar for the cultured species [see notes above]. Plates were then incubated in the same static incubator at $37^{\circ} \mathrm{C}$. Plates containing PA or SA incubated for $16 \mathrm{~h}$ and plates containing CA incubated for $24 \mathrm{~h}$ (as described above). Two independent serial dilutions of the same overnight culture were prepared and plated in parallel from the same overnight culture (constituting two technical replicates) and three independent biological replicates for each microbial species were performed across separate days using fresh microbial cultures and freshly prepared agar plates.

Statistical analysis

All biofilm data are represented as the mean \pm standard deviation (SD) of three separate biological replicates (collected simultaneously from the same culture vessel at each point of sampling) per timepoint across three independent biological experiments (conducted across different weeks) that were performed using fresh: ASM, microbial cultures and pieces of biofilm substrata [note that experiments using agar chunks or EVPL sections were performed independently of one another]. All planktonic data are represented as the mean \pm standard deviation (SD) of two technical replicates (collected simultaneously from the same culture vessel) per timepoint across three independent biological experiments. Planktonic and biofilm CFU $\mathrm{mL}^{-1}$ counts were performed in parallel from the same culture vessel. All statistical analysis was performed using GraphPad Prism version 8.2.0, with $P<0.05$ being considered statistically significant [statistical analysis can also be performed using R/Python packages stats/SciPy, respectively]. Paired group two-tailed t-tests were used to analyse: changes in $\mathrm{CFU} \mathrm{mL} \mathrm{mL}^{-1}$ counts of the different species present in single- or mixed-species biofilm samples collected at $\mathrm{T}=24 \mathrm{~h}$ or $96 \mathrm{~h}$; differences in CFU mL $\mathrm{mL}^{-1}$ counts of the microbial species present on either agar chunks or EVPL sections; and for comparisons of cell viability on selective and non-selective media. Changes in planktonic 
CFU $\mathrm{mL}^{-1}$ counts across the timepoints for each experiment were analysed using one-way repeated measures ANOVA. Differences in planktonic CFU $\mathrm{mL}^{-1}$ counts in cultures containing the different biofilm substrata across the timepoints for each experiment were analysed using two-way repeated measures ANOVA.

\section{Protocol for the use of this model}

Here we describe step-by-step the procedure used to prepare ASM and to set up/inoculate the continuous-flow culture vessel for the study of polymicrobial biofilm and planktonic communities. Reagents and equipment used in this study are listed in Table 2 and Table 3, respectively.

1. Step 1 Assembly of the biofilm containers. This can be done any time prior to making ASM. A wire "bucket" was crafted by hand from stainless steel wire gauze (Fischer Scientific). Figure 2 shows an image of a completed container and dimensions. Wire cutters are used to trim a mesh of stainless-steel gauze to a rectangle approximately $150 \mathrm{~mm} \times 40 \mathrm{~mm}$. The gauze was then carefully rolled into a cylinder with an approximate diameter of $25 \mathrm{~mm}$. The protruding cut ends of the wire mesh on the side of the cylinder were threaded through the adjacent mesh to secure the side of the cylinder in place. The height of the bucket was then adjusted to $35 \mathrm{~mm}$ via trimming with the wire cutters. Spare lengths of wire thread were then woven across the base of the container to generate a bucket-like structure (Figure 2B). Note that we ensured that there was a hole in the bottom of the bucket large enough to fit the out-flow tubing ( $3 \mathrm{~mm}$ diameter) (Step 6$)$. To keep the stainlesssteel container from interfering with the magnetic stirrer, and to allow easy removal of substratum material during cultivation, we suspended the bucket via two wire "arms" from a loop of silicone tubing threaded through two unused ports of the HPLC screw cap lid (Figure 2C). The wire arms were made by entwining three strands of stainless-steel wire and threading these through the mesh at the top of the bucket. The protruding portion of the arms were bent to allow the bucket assembly to be draped over the silicone tubing support loop and trimmed in length to $45 \mathrm{~mm}$. The correct length of these container arms is important to ensure that the bucket is completely submerged in the culture medium throughout incubation (Figure 2D).

2. Step 2 Preparation of ASM (day 1). Add $5 \mathrm{~g}$ of Type II mucin from porcine stomach to $250 \mathrm{~mL}$ phosphate buffered saline ( $\mathrm{pH} 7.4)$ and leave to dissolve overnight with stirring ( $400 \mathrm{rpm})$ at $4^{\circ} \mathrm{C}$. On the same day, add $4 \mathrm{~g}$ of deoxyribonucleic acid from salmon sperm to $250 \mathrm{~mL}$ autoclaved milliQ water and leave to dissolve overnight in a shaking water bath $\left(200 \mathrm{rpm}, 30^{\circ} \mathrm{C}\right)$. While the mucin/DNA is dissolving, prepare the amino acid and salt/buffer stock solutions ( $50 \mathrm{~mL}$ of each) according to Table 4 . Most amino acid stock solutions can be kept for one month in the dark at $4^{\circ} \mathrm{C}$. However, stock solutions of tyrosine, threonine, cysteine, phenylalanine and histidine must be made freshly for each batch of ASM.

3. Step 3 Preparation of ASM (day 2). Add ammonium chloride ( $0.124 \mathrm{~g})$, potassium chloride (1.116 g), sodium chloride (3.032 g) and 3-( $N$-morpholino) propanesulfonic acid (MOPS, $2.092 \mathrm{~g}$ ) to a $1 \mathrm{~L}$ beaker and dissolve in $250 \mathrm{~mL}$ milliQ water with gentle stirring $(50 \mathrm{rpm})$. Then add the remaining salts and amino acids from the premade stock solutions as shown in Table 4. Next, combine the dissolved DNA and mucin solutions and add to the beaker with gentle mixing $(50 \mathrm{rpm})$ for $5 \mathrm{~min}$, or until the solution is homogenous. Adjust to $\mathrm{pH} 6.8$ with $0.1 \mathrm{M}$ acetic acid or $0.1 \mathrm{M}$ potassium hydroxide. Following this, prepare the remaining media solutions and add them to the beaker according to Table 5 alongside $5 \mathrm{~mL}$ egg yolk emulsion. Once fully homogenous, adjust the total volume to $1 \mathrm{~L}$ with milliQ water. The ASM is then filter sterilised using a $1 \mathrm{~L}$ disposable Stericup filter unit $(0.22 \mu \mathrm{M}$ pore size) attached to a large diaphragm vacuum pump. Note that the filtering process is slow and may take 2-3 days to complete. Half-way through filtering we recommend carefully decanting (into a clean beaker) the unfiltered ASM from the Stericup unit and rinsing the top of the filter membrane with several $\mathrm{mL}$ of sterile PBS (that is then discarded) and then continuing with the filtration to speed up this process.

4. Step 4 Assembly of continuous-flow culture vessel (day 3). While the ASM is being filter-sterilised, assemble the continuous-flow culture vessel as outlined below with inclusion of the biofilm bucket constructed in Step 1 . The continuous-flow culture vessel consists of a $100 \mathrm{~mL}$ Duran flask fitted with an assembled GL-80 4-port HPLC screw cap (Duran). Two lengths of $1.5 \mathrm{~mm}$ bore sterlin silicone tubing (Fisher Scientific) were fed into two of the HPLC ports to act as an inlet/outlet (respectively) for the medium. To prevent contamination of the media reservoir with motile bacteria, ensure that only the outlet tube is in contact with the culture medium when the vessel is filled with ASM. A short piece of silicone tubing was threaded through the two-remaining unused HPLC ports (diagonal from one another) and secured tightly before sealing any gaps around the HPLC ports with parafilm. The biofilm bucket (assembled in Step 1) was hooked onto the suspended tubing and, using forceps, the outlet tube was gently pulled through the meshed hole in the base of the bucket (see step 1). A clean magnetic stir bar was placed in the culture vessel and the fully-assembled lid was fitted. Finally, the inlet tubing 
Table 2. Reagents used in this study.

\begin{tabular}{|c|c|}
\hline Reagent & Supplier [Catalogue Number] \\
\hline Mucin from porcine stomach (Type II) & Merck [M2378] \\
\hline Deoxyribonucleic acid from salmon sperm & Merck [31149] \\
\hline Phosphate buffered saline & Oxoid [BR0014G] \\
\hline$L$-serine & Merck [S4500] \\
\hline L-glutamic acid hydrochloride & Merck [G2128] \\
\hline L-proline & Merck [P8865] \\
\hline L-glycine & Merck [G7126] \\
\hline$L$-alanine & Merck [A7627] \\
\hline L-valine & Merck [V0500] \\
\hline L-methionine & Merck [M9625] \\
\hline L-isoleucine & Merck [I2752] \\
\hline L-leucine & Merck [L8000] \\
\hline L-ornithine hydrochloride & Merck [W419001] \\
\hline L-lysine hydrochloride & Merck [W384712] \\
\hline$L$-arginine monohydrochloride & Merck [A5131] \\
\hline L-tryptophan & Merck [T0254] \\
\hline$L$-asparagine monohydrate & Merck [A8381] \\
\hline L-tyrosine & Merck [T3754] \\
\hline L-threonine & Merck [T8625] \\
\hline L-cystine dihydrochloride & Merck [C6727] \\
\hline L-phenylalanine & Merck [P2126] \\
\hline L-histidine monohydrochloride monohydrate & Merck [H8125] \\
\hline Sodium phosphate monobasic anhydrous & Fisher Scientific [7558-80-7] \\
\hline Sodium phosphate dibasic anhydrous & Fisher Scientific [7558-79-4] \\
\hline Potassium nitrate & Fisher Scientific [7757-79-1] \\
\hline Potassium sulfate & Fisher Scientific [7778-80-5] \\
\hline Ammonium chloride & Merck [12125-02-9] \\
\hline Sodium chloride & Fisher Scientific [7647-14-5] \\
\hline Potassium chloride & Fisher Scientific [7447-40-7] \\
\hline MOPS [3-(N-morpholino)-propanesulfonic acid] & Melford [1132-61-2] \\
\hline$D-(+)$-glucose (dextrose) & Merck [G7021] \\
\hline$L-(+)$-lactic acid & Merck [L1750] \\
\hline Calcium chloride dihydrate & Merck [10035-04-8] \\
\hline Magnesium chloride hexahydrate & Merck [7791-18-6] \\
\hline Iron (II) sulfate heptahydrate & Merck [7782-63-0] \\
\hline$N$-acetyl- $D$-glucosamine & Merck [A8625] \\
\hline Egg yolk emulsion & Millipore [17148] \\
\hline Pseudomonas isolation agar & Oxoid [CM0559] \\
\hline Mannitol salt agar & Oxoid [CM0085] \\
\hline BiGGY-agar & Oxoid [CM0589] \\
\hline Agar & Formedium [009002-18-0] \\
\hline Lysogeny broth & Formedium [LBX0102] \\
\hline Dulbecco's Modified Eagle Medium & Merck [D5030] \\
\hline Roswell Park Memorial Institute 1640 Medium & Merck [R8758] \\
\hline
\end{tabular}


Table 3. Equipment used in this study.

\begin{tabular}{|c|c|}
\hline Equipment & Supplier [Catalogue Number] \\
\hline $100 \mathrm{~mL}$ Duran Flask & Merck [Z232076] \\
\hline 4-port HPLC GL80 Screw Cap & Fisher Scientific [10583913] \\
\hline 24-channel IPC ISM934C Standard-speed Digital Peristaltic Pump & Cole-Parmer [WZ-78001-42] \\
\hline $1.5 \mathrm{~mm}$ Bore Sterilin Silicon Tubing & ThermoFisher [TSR0150150P] \\
\hline Stainless Steel Wire Gauze & Fisher Scientific [12958950] \\
\hline Velp 6-position Multiposition Digital Stirrer & Cole-Parmer [F203A0179] \\
\hline Round White PTFE Magnetic Stir Bar, Length $20 \mathrm{~mm} \times$ Diameter $8 \mathrm{~mm}$ & Merck [HS120548] \\
\hline Swann-Morton Number 21 Carbon Steel Scalpel Blade & Fisher Scientific [11778363] \\
\hline Epredia Shandon $12.7 \mathrm{~cm}$ Cartilage Fine Point Curved Thumb Forceps & Fisher Scientific [15307805] \\
\hline Epredia Shandon $16.5 \mathrm{~cm}$ Straight Dissecting Scissors (Sharp Ended) & Fisher Scientific [15202290] \\
\hline $25 \mathrm{~cm}$ Eisco Palette Knife Spatula & Fisher Scientific [S80827] \\
\hline Azpack Carbon Steel Razor Blades & Fisher Scientific [11904325] \\
\hline Microspec $5 \mu \mathrm{L}$ Nichrome Microbial inoculation Loop & Fisher Scientific [15712175] \\
\hline 30 mL Polystyrene Universal Tube (Sterile) & Starlab [E1412-3011] \\
\hline Eppendorf BioSpectrometer Kinetic & Eppendorf [6136000819] \\
\hline $2.38 \mathrm{~mm}$ Diameter Metal Beads & Qiagen [13118-400] \\
\hline $2 \mathrm{~mL}$ PowerBead Beating Tubes & Qiagen [13116-50] \\
\hline FastPrep-24 5G benchtop homogeniser & MP Biomedicals [116005500] \\
\hline Stericup Quick Release-GP Sterile Vacuum Filtration System & Merck [S2GPU10RE] \\
\hline Nunc Cell-Culture Treated 24-well Plate & ThermoFisher [142475] \\
\hline Sterile $90 \mathrm{~mm} \times 15 \mathrm{~mm}$ Petri Dishes & Merk [Z717223] \\
\hline Bemis Parafilm M Laboratory Wrapping & Fisher Scientific [HS234526B] \\
\hline
\end{tabular}

was wrapped in aluminium foil and the entire assembly was autoclaved. The setup was allowed to completely dry overnight (in a drying cabinet) before use.

5. Step 5 Preparation of biofilm substratum (day 3). (i) Using agar chunks as a solid substratum for biofilm formation, prepare the substratum by suspending $2.5 \mathrm{~g}$ of agar in $100 \mathrm{~mL}$ milliQ water. Autoclave. Once cooled, but still warm $\left(\sim 65^{\circ} \mathrm{C}\right)$, pour the agar to a depth of $5 \mathrm{~mm}$ in a sterile $90 \mathrm{~mm}$ petri dish. Once set, the agar plates can be wrapped in parafilm and kept at $4^{\circ} \mathrm{C}$ until the day of use. (ii) Ex vivo porcine lung (EVPL) tissue sections can also be used as an alternative substratum for biofilm formation. Please refer to Step 7 (day 4) for the protocol detailing the inclusion of EVPL tissue sections in the model.

6. Step 6 Preparation of overnight microbial cultures (day 3). Place a nichrome $5 \mu \mathrm{L}$ microbial inoculation loop into the blue flame of a Bunsen burner for $5 \mathrm{~s}$. Allow the loop to cool then pick a single microbial colony from an agar plate and use to inoculate $10 \mathrm{~mL}$ of $\mathrm{LB}$ in a sterile $30 \mathrm{~mL}$ universal tube. Repeat for all microbial strains to be inoculated into the culture vessel, then place the tubes on a rotating drum $(200 \mathrm{rpm})$ and incubate at $37^{\circ} \mathrm{C}$ overnight.

7. Step 7 Preparation of EVPL biofilm substratum (day 4). This work was conducted in collaboration with Dr Freya Harrison at the University of Warwick following their previously published protocol for the preparation of EVPL sections (Harrison et al., 2014) Prior to culture vessel assembly and inoculation (see steps 8-9 below), fresh pig lungs were collected from the butchers and processed within the hour. To remove surface contaminants, a $25 \mathrm{~cm}$ palette knife was heated using a Bunsen burner and briefly tapped $(<1 \mathrm{~s})$ on the area to be dissected. A sterile razor blade was used to excise the bronchiole and remove all alveolar tissue. Bronchioles were then washed in DMEM/RPMI solution (40 mL, 50:50 ratio) and cut into $5 \mathrm{~mm}$ wide strips with sterile dissection scissors. The strips were washed in DMEM/RPMI and cut into $5 \mathrm{~mm} \times 5 \mathrm{~mm}$ squares. EVPL sections 
Table 4. Amino acid and salt stock solutions and volumes needed to make 1 L ASM.

\begin{tabular}{|c|c|c|c|c|c|c|}
\hline Chemical & $\begin{array}{l}\text { Mass to } \\
\text { add } \\
\text { (g) }\end{array}$ & $\begin{array}{l}\text { Stock } \\
\text { volume } \\
(\mathrm{mL})\end{array}$ & $\begin{array}{l}\text { Stock } \\
\text { conc } \\
\text { (M) }\end{array}$ & $\begin{array}{l}\text { Stock to add } \\
\text { to beaker } \\
(\mathrm{mL})\end{array}$ & $\begin{array}{l}\text { Final } \\
\text { Conc } \\
(\mathrm{mM})\end{array}$ & Notes \\
\hline L-serine & 0.525 & 50 & 0.1 & 14.46 & 1.446 & - \\
\hline L-glutamic acid hydrochloride & 0.918 & 50 & 0.1 & 15.492 & 1.549 & - \\
\hline L-proline & 0.576 & 50 & 0.1 & 16.612 & 1.661 & - \\
\hline L-glycine & 0.375 & 50 & 0.1 & 12.032 & 1.203 & - \\
\hline$L$-alanine & 0.445 & 50 & 0.1 & 17.8 & 1.78 & - \\
\hline L-valine & 0.586 & 50 & 0.1 & 11.172 & 1.117 & - \\
\hline$L$-methionine & 0.746 & 50 & 0.1 & 6.332 & 0.633 & - \\
\hline L-isoleucine & 0.656 & 50 & 0.1 & 11.212 & 1.121 & - \\
\hline L-leucine & 0.656 & 50 & 0.1 & 16.092 & 1.609 & - \\
\hline L-ornithine hydrochloride & 0.843 & 50 & 0.1 & 6.76 & 0.676 & - \\
\hline L-lysine hydrochloride & 0.913 & 50 & 0.1 & 21.28 & 2.128 & - \\
\hline $\begin{array}{l}L \text {-arginine } \\
\text { monohydrochloride }\end{array}$ & 1.054 & 50 & 0.1 & 3.06 & 0.306 & - \\
\hline L-tryptophan & 1.021 & 50 & 0.1 & 0.132 & 0.013 & $\begin{array}{l}\text { Prep in } \\
0.2 \mathrm{M} \mathrm{NaOH}\end{array}$ \\
\hline L-asparagine monohydrate & 0.666 & 50 & 0.1 & 8.272 & 0.827 & $\begin{array}{l}\text { Prep in } \\
0.5 \mathrm{M} \mathrm{NaOH}\end{array}$ \\
\hline L-tyrosine & 0.906 & 50 & 0.1 & 8.02 & 0.802 & $\begin{array}{l}\text { Prep in } \\
1.0 \mathrm{M} \mathrm{NaOH} \\
\text { Make fresh }\end{array}$ \\
\hline L-threonine & 0.596 & 50 & 0.1 & 10.72 & 1.072 & Make fresh \\
\hline L-cystine dihydrochloride & 0.788 & 50 & 0.1 & 1.6 & 0.16 & Make fresh \\
\hline L-phenylalanine & 0.826 & 50 & 0.1 & 5.3 & 0.53 & Make fresh \\
\hline $\begin{array}{l}\text { L-histidine } \\
\text { monohydrochloride } \\
\text { monohydrate }\end{array}$ & 1.048 & 50 & 0.1 & 5.192 & 0.519 & Make fresh \\
\hline $\begin{array}{l}\text { Sodium phosphate monobasic } \\
\text { anhydrous }\end{array}$ & 1.380 & 50 & 0.2 & 8.125 & 1.3 & - \\
\hline $\begin{array}{l}\text { Sodium phosphate dibasic } \\
\text { anhydrous }\end{array}$ & 1.420 & 50 & 0.2 & 6.252 & 1.25 & - \\
\hline Potassium nitrate & 5.056 & 50 & 1 & 0.348 & 0.348 & - \\
\hline Potassium sulfate & 2.178 & 50 & 0.25 & 1.084 & 0.271 & - \\
\hline
\end{tabular}

Table 5. Reagents to make 1 L ASM after addition of the mucin-DNA solution and pH adjustment to pH 6.8.

\begin{tabular}{|c|c|c|c|c|c|c|}
\hline Chemical & $\begin{array}{l}\text { Mass to } \\
\text { add } \\
\text { (g) }\end{array}$ & $\begin{array}{l}\text { Stock } \\
\text { volume } \\
(\mathrm{mL})\end{array}$ & $\begin{array}{l}\text { Stock } \\
\text { conc } \\
\text { (M) }\end{array}$ & $\begin{array}{l}\text { Stock to add } \\
\text { to beaker } \\
(\mathrm{mL})\end{array}$ & $\begin{array}{l}\text { Final } \\
\text { Conc } \\
(\mathrm{mM})\end{array}$ & Notes \\
\hline$D-(+)$-glucose (dextrose) & 4.504 & 25 & 1 & 1.2 & 3 & - \\
\hline$L$-(+)-lactic acid & 2.252 & 25 & 1 & 9.3 & 9.3 & $\begin{array}{l}\text { pH stock to } 7 \\
\text { with } \mathrm{NaOH}\end{array}$ \\
\hline $\begin{array}{l}\text { Calcium chloride } \\
\text { dihydrate }\end{array}$ & 3.67535 & 25 & 1 & 1.754 & 1.754 & - \\
\hline $\begin{array}{l}\text { Magnesium chloride } \\
\text { hexahydrate }\end{array}$ & 5.08275 & 25 & 1 & 0.606 & 0.606 & - \\
\hline $\begin{array}{l}\text { Iron (II) sulfate } \\
\text { heptahydrate }\end{array}$ & 0.05 & 50 & 0.0036 & 1 & 0.0036 & Make fresh \\
\hline$N$-acetyl-D-glucosamine & 1.383 & 25 & 0.25 & 1.2 & 0.3 & - \\
\hline
\end{tabular}


were washed again in DMEM/RPMI, then transferred to a petri dish containing $40 \mathrm{~mL}$ ASM and irradiated in UV lightbox for $5 \mathrm{~min}$ before being aseptically transferred to the biofilm container (as in Step 8).

8. Step 8 Assembly of the culture vessel (day 4). Working in a microbiological safety cabinet, cut the agar into $5 \mathrm{~mm} \times 5 \mathrm{~mm}$ cubes using sterile (autoclaved) scalpel/forceps and aseptically transfer these into the wire mesh container so that they sit loose (not stacked) at the bottom of the bucket. The number of substratum pieces used for an experiment may differ, depending on the type of experiment, length of incubation and number of time points to be sampled. In the current work, we simply report the microbial composition of polymicrobial biofilms at two time points $(\mathrm{T}=24 \mathrm{~h}$ and $96 \mathrm{~h}$ ). Hence, only six pieces of substratum were incubated in the culture vessel (three for each time point). However, we note that each biofilm container can easily hold $30+$ pieces of substratum. Next, aseptically transfer $100 \mathrm{~mL}$ of fresh ASM to the culture vessel and secure the lid, ensuring that the biofilm container does not interfere with the magnetic stir bar and is fully submerged in the ASM. The inlet tubing was carefully unwrapped from the foil and placed into the remaining ASM (forming the media reservoir) with the top sealed well with sterile parafilm to prevent contamination. Finally, place the end of the outlet tubing into a discard jar and connect the inlet/outlet tubing to a peristaltic pump. Figure 1 shows a schematic diagram of the assembled continuous-flow culture vessel. The entire system can then be primed with media. The setup was pre-warmed at $37^{\circ} \mathrm{C}$ prior to microbial inoculation.

9. Step 9 Culture vessel inoculation and incubation (day 4). In this report we describe the formation of polymicrobial biofilms of Pseudomonas aeruginosa (PA), Staphylococcus aureus (SA) and Candida albicans (CA), although in principle, any combination of microbial species could be used for co-culture. Overnight cultures (prepared on day 3 ) of each species were washed three times in sterile PBS prior to inoculation. Once washed, the optical density $\left(\mathrm{OD}_{600}\right)$ of the cultures was measured and each species was introduced into the culture vessel to achieve a starting $\mathrm{OD}_{600}$ of 0.05 . The culture vessel was incubated at $37^{\circ} \mathrm{C}$, with $100 \mathrm{rpm}$ stirring using a round PTFE magnetic stir bar $(8 \mathrm{~mm}$ diameter $\times 20 \mathrm{~mm}$ length $)$, for three hours prior to starting the flow of medium. For the current study, a continuous flow rate of $145 \mu \mathrm{L} \mathrm{min}{ }^{-1}$ was applied for the remaining period of incubation $(96 \mathrm{~h}$ ). From our previous study (O'Brien and Welch, 2019a), we note that the flow rate may need to be experimentally optimised if the goal is to maintain steady-state cultures of other species or strains.

10. Step 10 Sample removal and viable cell counts (Day 4-9). At the desired time point(s) (in this study, $\mathrm{T}=24 \mathrm{~h}$ and $96 \mathrm{~h}$ for the biofilms and $\mathrm{T}=24,48,72$ and $96 \mathrm{~h}$ for the planktonic samples) remove $1 \mathrm{~mL}$ aliquots of the liquid culture using a sterile serological pipette, or pieces of the biofilm substratum from the biofilm bucket, as necessary. For enumeration of colony forming units $\left(\mathrm{CFU} \mathrm{mL} \mathrm{mL}^{-1}\right)$ from the biofilm samples, remove pieces of solid substratum using sterile forceps, taking care to flame and cool the forceps between the collection of individual samples. Pieces of the substratum were aseptically transferred to $500 \mu \mathrm{L}$ sterile PBS in a 24 -well plate. To remove any loosely attached planktonic cells, gently swirl the plates for approximately $5 \mathrm{~s}$ then transfer the substratum to another $500 \mu \mathrm{L}$ of fresh PBS. Repeat the process two more times. A washed piece of substratum was then transferred to a $2 \mathrm{~mL}$ bead beating tube containing $1 \mathrm{~mL}$ PBS and eighteen $2.38 \mathrm{~mm}$ diameter metal beads (Qiagen). The sample was homogenised in a Fast-Prep 5G benchtop homogeniser (MP biomedicals) for $40 \mathrm{~s}$ at $4 \mathrm{~m} \mathrm{~s}^{-1}$. Using a pipette, and taking care to avoid any solid pieces of biofilm substratum, the cell supernatant was removed and $\mathrm{CFU} \mathrm{mL} \mathrm{mL}^{-1}$ counts were determined as described in the Methods section above.

\section{Results \\ Characterisation of the biofilms formed in continuous flow conditions \\ (i) Agar as a solid substratum}

We first sought to discern changes in the microbial composition of single-species and polymicrobial biofilms grown on agar chunks as a substratum (Figure 5 and underlying data (O'Brien et al., 2021)). Viable cell counts were determined on selective agar plates after rinsing each $5 \mathrm{~mm}$ agar chunk (with attached biofilm) and resuspending the attached cells in $1 \mathrm{~mL}$ PBS. When examining the single-species biofilm populations, titres of attached SA and CA were similar (ca. $10^{6}-10^{7} \mathrm{CFU} \mathrm{mL}{ }^{-1}$ ) after $24 \mathrm{~h}$ incubation, whereas titres of attached PA were $>10$-fold greater (at just under $10^{8} \mathrm{CFU} \mathrm{mL}{ }^{-1}$ ). However, over the next $72 \mathrm{~h}, \mathrm{PA}$ titres increased only slightly (albeit significantly) to $>10^{8} \mathrm{CFU} \mathrm{mL}^{-1}$, and SA titres rose to around the same level (i.e. to a titre $2 \operatorname{logs}$ greater than the titre at the $24 \mathrm{~h}$ time point). By contrast, CA titres remained essentially unchanged at the $96 \mathrm{~h}$ time point compared with the $24 \mathrm{~h}$ time point. These data suggest CA biofilms establish rapidly with little overall change in cell titres over time. By contrast, PA and SA biofilms also establish quickly, but continue to grow significantly between sampling points. 


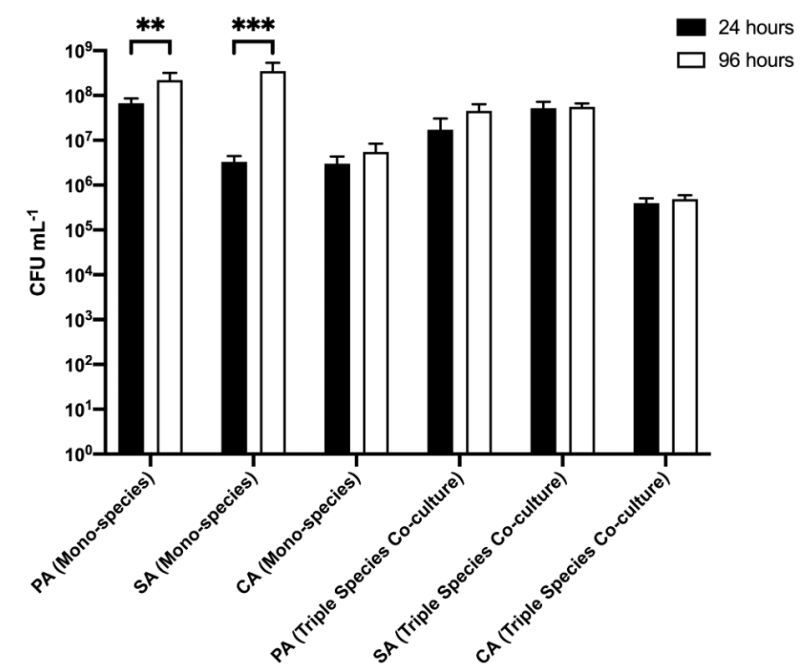

Figure 5. Cell titres derived from biofilms adhered to agar chunks. $P$. aeruginosa PAO1 (PA), S. aureus 25923 (SA) and C. albicans SC5314 (CA) cell counts (expressed as CFU mL ${ }^{-1}$ ) adhered to $2.5 \%(\mathrm{w} / \mathrm{v})$ agar chunks after incubation for $24 \mathrm{~h}$ (black bars) or $96 \mathrm{~h}$ (white bars) in the continuous-flow culture model. Asterisks indicate significant ( $* \star P<0.01, * \star \star P<0.001$ ) differences in CFU mL ${ }^{-1}$ counts between the $24 \mathrm{~h}$ and $96 \mathrm{~h}$ time points. Data represent the mean \pm standard deviation of three independent biological experiments in which three pieces of biofilm substratum were sampled per culture vessel per timepoint.

The situation was different in the polymicrobial cultures. Here, the titres of PA, SA, and CA present on the biofilm substrata removed sequentially from the same culture vessel remained essentially unchanged at the $24 \mathrm{~h}$ and $96 \mathrm{~h}$ sampling points (at around $10^{7} \mathrm{CFU} \mathrm{mL} \mathrm{m}^{-1}$ for PA and SA, and around $10^{5} \mathrm{CFU} \mathrm{mL}^{-1}$ for $\mathrm{CA}$ ). These data suggest that growth in a polymicrobial culture constrains the population size of individual species in a biofilm.

(ii) EVPL tissue sections as a solid substratum

We next examined biofilm formation on a different biofilm substratum, EVPL tissue (in place of agar chunks) (Figure 6 and underlying data (O'Brien et al., 2021)). No PA, SA or CA cells could be isolated from uninfected EVPL sections

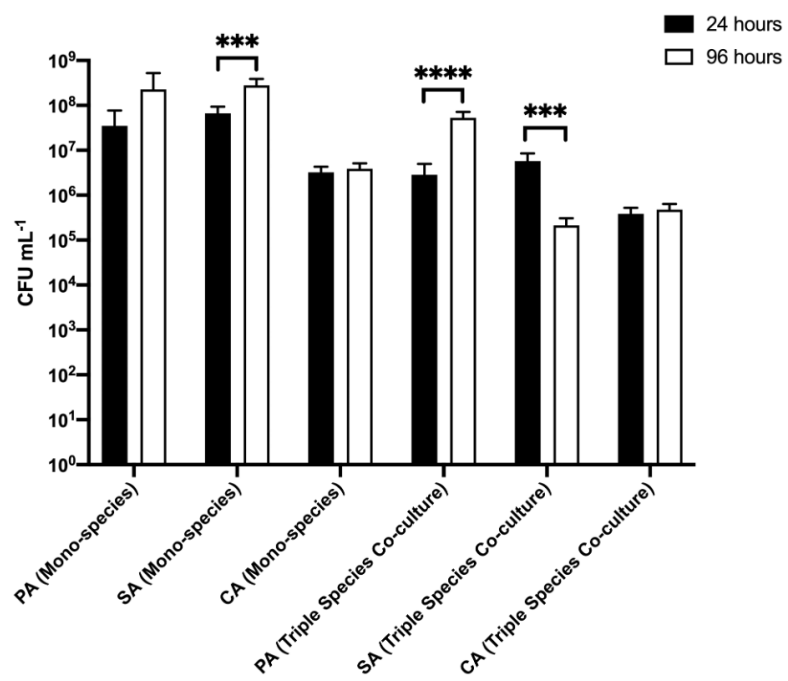

Figure 6. Cell titres derived from biofilms adhered to porcine bronchiole tissue. $P$. aeruginosa PAO1 (PA), S. aureus 25923 (SA) and C. albicans SC5314 (CA) cell counts (expressed as CFU mL ${ }^{-1}$ ) adhered to sections of ex vivo porcine lung tissue after incubation for $24 \mathrm{~h}$ (black bars) or $96 \mathrm{~h}$ (white bars) in the continuous-flow culture model. Asterisks indicate significant ( $* * * P<0.001, * \star * \star * P<0.0001$ ) differences in CFU mL ${ }^{-1}$ counts between the $24 \mathrm{~h}$ and $96 \mathrm{~h}$ time points. Data represent the mean \pm standard deviation of three independent biological experiments in which three pieces of biofilm substratum were sampled per culture vessel per timepoint. 
(A)

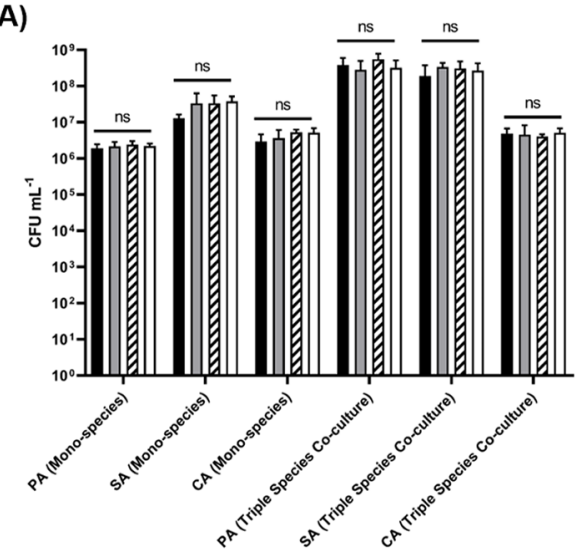

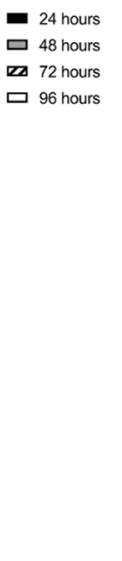

(B)

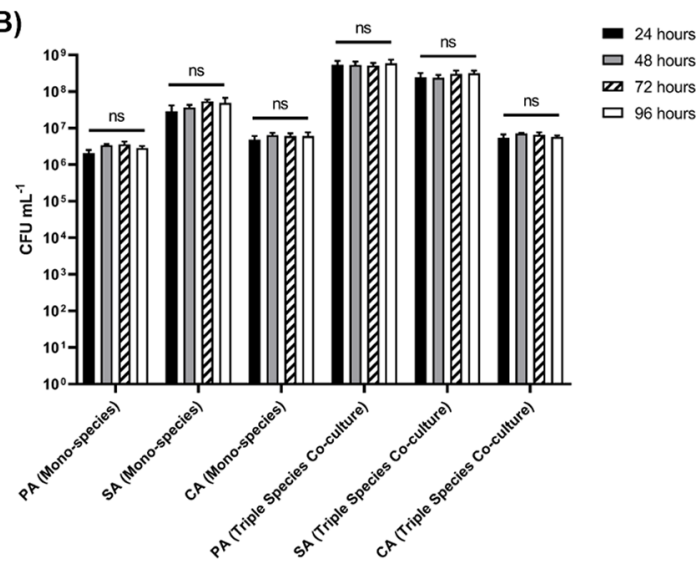

Figure 7. Cell titres of planktonic cultures. P. aeruginosa PAO1 (PA), S. aureus 25923 (SA) and C. albicans SC5314 (CA) cell counts (expressed as CFU mL ${ }^{-1}$ ) in the planktonic fraction of single-species and polymicrobial cultures incubated in ASM in the continuous-flow model containing (A) agar chunks or (B) ex vivo porcine lung tissue sections as the solid substrata. Data represent the mean \pm standard deviation of two technical replicates collected per timepoint from three independent biological experiments. $P>0.05$ is considered as not significantly different (ns).

after any period of incubation. In the single-species biofilm populations, there was no appreciable difference in PA or SA titres adhered to the substratum at the initial point of sampling $\left(10^{7}-10^{8} \mathrm{CFU} \mathrm{mL} \mathrm{m}^{-1}\right.$ at $\left.24 \mathrm{~h}\right)$. Adhered CA titres were consistently 10-fold lower (ca. $10^{6} \mathrm{CFU} \mathrm{mL}^{-1}$ ) at the same sampling point. After a further $72 \mathrm{~h}$ growth, $\mathrm{PA}$ and $\mathrm{SA}$ titres increased to $>10^{8} \mathrm{CFU} \mathrm{mL}{ }^{-1}$, whereas $\mathrm{CA}$ titres remained essentially unchanged compared with the titres measured at $24 \mathrm{~h}$. These data indicate that the dynamics of SA biofilm formation varies on different substrata; SA clearly shows more robust initial colonisation of EVPL substrata compared with agar chunks.

In the triple-species polymicrobial culture, there was no statistically significant difference in adhered PA or SA titres at the $24 \mathrm{~h}$ sampling point (both species achieving $10^{6}-10^{7} \mathrm{CFU} \mathrm{mL}^{-1}$ at $24 \mathrm{~h}$ ). We note that this is 10 -fold lower than the PA and SA titres at the same time point in the corresponding biofilms from axenic cultures. Similarly, CA titres in the polymicrobial biofilms were also 10 -fold lower than the $\mathrm{CA}$ titres in axenically-cultured biofilms. However, and whereas adhered CA titres in the polymicrobial biofilms remained unchanged over the following $72 \mathrm{~h}$, PA titres displayed a marked increase (attaining ca. $10^{8} \mathrm{CFU} \mathrm{mL}^{-1}$ by the $96 \mathrm{~h}$ time point) and SA titres displayed a marked decrease (falling to ca. $10^{5} \mathrm{CFU} \mathrm{mL}{ }^{-1}$ ) in adhered cell counts. We conclude that the population dynamics of each species can vary by orders of magnitude, depending on the nature of the biofilm substrata.

\section{Population structure of the planktonic fractions}

In parallel with the analysis of species titres in adhered biofilms, we also examined the corresponding titres of each species in the planktonic (i.e. non-attached) fraction (Figure 7 and underlying data (O'Brien et al., 2021)). Consistent with our previous findings (O'Brien and Welch, 2019a), steady-state microbial communities were established by $24 \mathrm{~h}$ incubation. There was no appreciable change in $\mathrm{CFU} \mathrm{mL} \mathrm{mL}^{-1}$ counts of any species cultured as part of an axenic or polymicrobial population across any point of sampling. Furthermore, there was no discernible difference in $\mathrm{CFU} \mathrm{mL} \mathrm{m}^{-1}$ counts of the planktonic communities grown in the culture vessel flasks containing agar chunks (Figure 7A) or EVPL tissue sections (Figure 7B). These data indicate that the population dynamics of the biofilms is distinct from the population dynamics of the surrounding planktonic culture.

\section{Discussion}

Here we report a simple method for the robust and reproducible growth of single- and multi-species biofilms on different substrata. Our model system has been designed to mimic the nutritional environment associated with $\mathrm{CF}$ airways. We previously showed (O'Brien and Welch, 2019a) that the model can maintain very stable steady-state polymicrobial populations of planktonic cells, even among species that would ordinarily outcompete one another during ex situ co-cultivation. In the current work, we extend these findings to show that polymicrobial biofilms can be similarly maintained. Remarkably, we also show that the biofilm composition is far more dynamic than that of the surrounding planktonic culture, and can vary substantially, even when the planktonic species profile is stable.

A major benefit of our model over existing in vivo approaches is that is inexpensive to set up and requires no specialist equipment or training to operate. Indeed, the only perceived barrier preventing wider uptake of the model is in preparation 
of the ASM culture medium. Mitigating, this generally requires only a few minutes of effort each day (once the stock solutions have been made up). The primary benefit of the model is that very stable polymicrobial communities can be rapidly established and maintained for extended periods of time, and that the planktonic and biofilm modes of growth can be studied concurrently in a single experiment. This enables the facile longitudinal study of polymicrobial communities in vitro, enabling experimental analyses that were previously not possible due to population instability. As such, the model allows researchers to explore previously inaccessible problems pertaining to microbial ecology, gene expression and metabolism in polymicrobial communities. For example, we are currently exploiting the system to examine how mixed-species biofilms such as those found in the CF airways form over time. We are also using the model to examine how the inclusion of different species or treatment with antimicrobial compounds affect the stability and dynamics of polymicrobial biofilms longitudinally.

Alongside the ethical benefits and accessibility of an in vitro model for microbial culture, the experimentally tuneable nature of our model system provides several inherent benefits over existing in vivo CF models (O'Brien and Welch, 2019b). ASM is a chemically-defined synthetic growth medium that has been formulated to closely mimic the nutritional composition of CF airway secretions (Kirchner et al., 2012; Palmer et al., 2005; Palmer et al., 2007; Turner et al., 2015; Cornforth et al., 2018). This allows subtle interspecies interactions to be quantified, in real-time, with great reproducibility. By contrast, the existing animal models display much greater variability, even within a single host species. Furthermore, culture conditions can be readily modified to enable the detailed study of how a particular variable (such as iron, for example) impinges upon the formation of polymicrobial biofilms (Mashburn et al., 2005; Palmer et al., 2005). This level of environmental control is near impossible to achieve with in vivo infection models. We also note that the experimentally facile nature of our system should permit the study of biofilm formation in other clinically-relevant polymicrobial infection scenarios such as non-CF bronchiectasis, asthma, or chronic obstructive pulmonary disorders (COPDs). This can be accomplished through the simple expedient of appropriately modifying the nutritional composition of the culture medium.

The key finding in this report is that mixed-species biofilms comprised of three very different CF-associated pathogens (a Gram-positive species (SA), a Gram-negative species (PA), and a fungal species (CA)) display distinctly different compositional dynamics compared with their planktonic counterparts. In particular, we note that the species profiles in polymicrobial biofilms are consistent with both antagonistic and synergistic interactions. For example, irrespective of the substrate, adhered CA titres were lower in the polymicrobial biofilms compared with CA titres in biofilms from axenic CA cultures.

The primary limitation of in vitro models of infection is a lack of spatial organisation and exclusion of host cells present when utilising in vivo infection models. We therefore attempted to redress this issue through the introduction of EVPL tissue sections as biofilm substrata. Porcine airways share a remarkable degree of structural homology with human airways (Judge et al., 2014; Rogers et al., 2008), and pig lungs are readily available from most butchers as a by-product of the food industry. Hence, the inclusion of ex vivo bronchiole tissue sections provide an ethically sustainable approach to introduce an element of host-microbe interaction and spatial organisation to the model (Harrington et al., 2020; Sweeney et al., 2021). Indeed, we note that growth on different solid substrata had a profound effect on the compositional dynamics of polymicrobial biofilms, especially with regards to $S$. aureus. SA is an effective early coloniser of the CF airways (Bogaert et al., 2004). When grown on EVPL sections, SA rapidly established a mono-species biofilm with significantly higher titres compared with the biofilm formed on agar chunks. This increased microbial attachment is consistent with the notion that SA adheres tightly to epithelial cells in the CF microenvironment (Josse et al., 2017), but is less effective at adhering to abiotic surfaces (agar chunks). However, and whereas SA titres on the agar chunk substrata were stable between the $24 \mathrm{~h}$ and $96 \mathrm{~h}$ sampling points, the SA titres on EVPL sections displayed a substantial decline over this period. By contrast, PA titres in the same biofilms increased, suggesting that the PA progressively displaces SA on the tissue surface. This reciprocal response (in terms of cell titres) by PA and SA was not observed when agar chunks were used as a substratum, suggesting that recognition of both airway epithelial cells and SA are required to drive the increased competitiveness by PA.

Despite the introduction of some level of spatial organisation (in the form of EVPL tissue), the major physiological limitation of our model compared with in vivo systems is a lack of live host cells and the absence of any accompanying host-microbe interactions that may modulate microbial behaviour. Nevertheless, and through our comparison of EVPL tissue and agar chunks as biofilm substrata, we note two things. First, the diminution in SA titres in polymicrobial biofilms after $96 \mathrm{~h}$ growth on EVPL tissue - a diminution not seen on agar chunk substrata - suggests that microbial interaction with the host tissue may up-regulate the localised production of virulence factors and enhance interspecies competition (Döring et al., 2011; Malhotra et al., 2019). The implication of this is that the growth of EVPL-associated biofilms in our continuous-flow model may enable the capture specific temporally-sensitive interactions between the host tissue and 
infecting microbes. Second, agar is a more suitable substratum for examining the long-term, steady-state growth of polymicrobial biofilms.

The ability to maintain very stable (in terms of composition) long-term polymicrobial biofilms in our setup using agar chunks as a solid substratum can be exploited for several other applications. First and most obviously, the setup can be used to investigate the species specificity (for example) of novel antimicrobial or anti-biofilm agents. Using our system, it is possible to test both a sustained treatment regimen (achieved by adding the test compound(s) at the desired concentration to the media reservoir) or a short-term treatment regimen, via adding a compound directly to the culture vessel through the injection ports. The latter may loosely mimic the metabolism and excretion of antimicrobials in situ. This degree of temporal control is not possible using existing in vivo or in vitro models. Second, new species or strain variants can be introduced to pre-established polymicrobial biofilms (e.g. addition of PA to a PA-negative community), allowing facile examination of the impact made by new species or variants. This is directly analogous to the situation seen in $\mathrm{CF}$, where the acquisition of new microbial species or variants can lead to major prognostic changes in the patient. It is important to note that whenever a new species is introduced, the medium flowrate $(Q)$ may need to be re-optimized. If $Q$ is too high, slower-growing organisms may be "washed out" and lost from the culture vessel. Conversely, if $Q$ is too low, species will grow faster than the rate of media displacement, causing elements of the population to exhaust key nutrients and enter the stationary phase of growth.

\section{Conclusions}

In summary, we present here a simple system for the study of CF-associated polymicrobial biofilms. Importantly, we have shown that polymicrobial biofilms display distinctly different population dynamics compared with the surrounding planktonic cells. Moreover, the compositional dynamics of the biofilms depends very much on the substratum employed. To further extend the utility of our model, we are currently adapting it for use with a wider range of CF-associated pathogens and testing the possibility of inoculating the system directly with CF patient-derived sputum.

\section{Data availability}

Underlying data

Figshare: Underlying data for 'An in vitro model for the cultivation of polymicrobial biofilms under continuous-flow conditions'. https://doi.org/10.6084/m9.figshare.14974479.v1 (O'Brien et al., 2021).

This project contains the following underlying data:

- EVPL Biofilms CFUs

- EVPL Supernatant CFUs

- Agar chunks Biofilm CFUs

- Agar chunks Supernatant CFUs

- Selective vs non-selective agar

Data are available under the terms of the Creative Commons Attribution 4.0 International license (CC-BY 4.0).

References

Ahmed B, Cox MJ, Cuthbertson L, et al.: Longitudinal development of the airway microbiota in infants with cystic fibrosis. Sci Rep. 2019; 9 :

5143.

PubMed Abstract | Publisher Full Text | Free Full Text

Antonic V, Stojadinovic A, Zhang B, et al.: Pseudomonas aeruginosa induces pigment production and enhances virulence in a white

phenotypic variant of Staphylococcus aureus. Infect Drug Resist. 2013; 6 :

175-186.

PubMed Abstract | Publisher Full Text | Free Full Text
Armbruster CR, Wolter DJ, Mishra M, et al.: Staphylococcus aureus Protein A Mediates Interspecies Interactions at the Cell Surface of Pseudomonas aeruginosa. $m B i o .2016 ; 7$.

PubMed Abstract | Publisher Full Text | Free Full Text

Baldan R, Cigana C, Testa F, et al.: Adaptation of Pseudomonas aeruginosa in Cystic Fibrosis airways influences virulence of Staphylococcus aureus in vitro and murine models of co-infection. PLoS One. 2014; 9: e89614.

PubMed Abstract | Publisher Full Text | Free Full Text 
Barnabie PM, Whiteley M: Iron-Mediated Control of Pseudomonas aeruginosa-Staphylococcus aureus Interactions in the Cystic Fibrosis Lung.J Bacteriol. 2015; 197: 2250-2251.

PubMed Abstract | Publisher Full Text | Free Full Text

Bayes HK, Ritchie N, Irvine S, et al.: A murine model of early Pseudomonas aeruginosa lung disease with transition to chronic infection. Sci Rep. 2016; 6: 35838 .

PubMed Abstract | Publisher Full Text | Free Full Text

Beaume M, Köhler T, Fontana T, et al.: Metabolic pathways of Pseudomonas aeruginosa involved in competition with respiratory bacterial pathogens. Front Microbiol. 2015; 6: 321.

PubMed Abstract | Publisher Full Text | Free Full Text

Bjarnsholt T, Jensen $P$, Fiandaca MJ, et al.: Pseudomonas aeruginosa biofilms in the respiratory tract of cystic fibrosis patients. Pediatr Pulmonol. 2009; 44: 547-558.

PubMed Abstract | Publisher Full Text

Bogaert D, Van Belkum A, Sluijter M, et al.: Colonisation by Streptococcus pneumoniae and Staphylococcus aureus in healthy children. Lancet. 2004; 363: 1871-1872.

PubMed Abstract | Publisher Full Text

Bonfield T, Chmiel JF: Impaired innate immune cells in cystic fibrosis: Is it really a surprise? J Cyst Fibros. 2017; 16: 433-435.

PubMed Abstract | Publisher Full Text

Boutin S, Graeber SY, Weitnauer M, et al.: Comparison of microbiomes from different niches of upper and lower airways in children and adolescents with cystic fibrosis. PLoS One. 2015; 10: e0116029.

PubMed Abstract | Publisher Full Text | Free Full Text

Briaud P, Camus L, Bastien S, et al.: Coexistence with Pseudomonas aeruginosa alters Staphylococcus aureus transcriptome, antibiotic resistance and internalization into epithelial cells. Sci Rep. 2019; 9: 16564.

PubMed Abstract | Publisher Full Text | Free Full Text

Carmody LA, Zhao J, Kalikin LM, et al.: The daily dynamics of cystic fibrosis airway microbiota during clinical stability and at exacerbation. Microbiome. 2015; 3: 12. PubMed Abstract | Publisher Full Text | Free Full Text

Cash HA, Woods DE, Mccullough B, et al.: A rat model of chronic respiratory infection with Pseudomonas aeruginosa. Am Rev Respir Dis. 1979; 119: 453-459.

PubMed Abstract | Publisher Full Text

Chattoraj SS, Murthy R, Ganesan S, et al.: Pseudomonas aeruginosa alginate promotes Burkholderia cenocepacia persistence in cystic fibrosis transmembrane conductance regulator knockout mice. Infect Immun. 2010; 78: 984-993.

PubMed Abstract | Publisher Full Text | Free Full Text

Chmiel JF, Davis PB: State of the art: why do the lungs of patients with cystic fibrosis become infected and why can't they clear the infection? Respir Res. 2003; 4: 8

PubMed Abstract | Publisher Full Text | Free Full Text

Cohen TS, Prince A: Cystic fibrosis: a mucosal immunodeficiency syndrome. Nat Med. 2012; 18: 509-519.

PubMed Abstract | Publisher Full Text | Free Full Text

Cornforth DM, Dees JL, Ibberson CB, et al.: transcriptome during human infection. Proc Natl Acad Sci U S A. 2018; 115: E5125-E5134.

Dalton T, Dowd SE, Wolcott RD, et al.: An in vivo polymicrobial biofilm wound infection model to study interspecies interactions. PLOS One. 2011; 6: e27317.

PubMed Abstract | Publisher Full Text | Free Full Text

Diggle SP, Griffin AS, Campbell GS, et al.: Cooperation and conflict in quorum-sensing bacterial populations. Nature. 2007; 450: 411-414. PubMed Abstract | Publisher Full Text

DÖRing G, Parameswaran IG, Murphy TF: Differential adaptation of microbial pathogens to airways of patients with cystic fibrosis and chronic obstructive pulmonary disease. FEMS Microbiol Rev. 2011; 35: 124-146.

PubMed Abstract | Publisher Full Text

Elborn JS: Cystic fibrosis. Lancet. 2016; 388: 2519-2531.

PubMed Abstract | Publisher Full Text

Elias S, Banin E: Multi-species biofilms: living with friendly neighbors. FEMS Microbiol Rev. 2012; 36: 990-1004.

PubMed Abstract | Publisher Full Text

Folkesson A, Jelsbak L, Yang L, et al.: Adaptation of Pseudomonas aeruginosa to the cystic fibrosis airway: an evolutionary perspective. Nat Rev Microbiol. 2012; 10: 841-851.

PubMed Abstract | Publisher Full Text

Frapwell C], Howlin RP, Soren O, et al.: Increased rates of genomic mutation in a biofilm co-culture model of Pseudomonas aeruginosa and Staphylococcus aureus. BioRx. 2018.

Publisher Full Text

Fux CA, Costerton JW, Stewart PS, et al.: Survival strategies of infectious biofilms. Trends Microbiol. 2005; 13: 34-40.

PubMed Abstract | Publisher Full Text
Gillum AM, Tsay EY, Kirsch DR: Isolation of the Candida albicans gene for orotidine-5'-phosphate decarboxylase by complementation of S. cerevisiae ura3 and E. coli pyrF mutations. Mol Gen Genet. 1984; 198: 179-182.

PubMed Abstract | Publisher Full Text

Guilbault C, Saeed Z, Downey GP, et al.: Cystic fibrosis mouse models. Am J Respir Cell Mol Biol. 2007; 36: 1-7.

PubMed Abstract |Publisher Full Text

Haley CL, Colmer-Hamood JA, Hamood AN: Characterization of biofilmlike structures formed by Pseudomonas aeruginosa in a synthetic

mucus medium. BMC Microbiol. 2012; 12: 181.

PubMed Abstract | Publisher Full Text | Free Full Text

Harrington NE, Sweeney E, Alav I, et al.: Antibiotic Efficacy Testing in an ex vivo Model of Pseudomonas aeruginosa and Staphylococcus aureus Biofilms in the Cystic Fibrosis Lung. J Vis Exp. 2021.

PubMed Abstract |Publisher Full Text

Harrington NE, Sweeney E, Harrison F: Building a better biofilm -

Formation of. Biofilm. 2020; 2: 100024

PubMed Abstract | Publisher Full Text | Free Full Text

Harrison F, Diggle SP: An ex vivo lung model to study bronchioles infected with Pseudomonas aeruginosa biofilms. Microbiology. 2016 162: $1755-1760$.

PubMed Abstract | Publisher Full Text

Harrison F, Muruli A, Higgins S, et al.: Development of an ex vivo porcine lung model for studying growth, virulence, and signaling of

Pseudomonas aeruginosa. Infect Immun. 2014; 82: 3312-3323.

PubMed Abstract | Publisher Full Text | Free Full Text

Hibbing ME, Fuqua C, Parsek MR, et al.: Bacterial competition: surviving and thriving in the microbial jungle. Nat Rev Microbiol. 2010; 8: 15-25.

PubMed Abstract | Publisher Full Text | Free Full Text

Hoffman LR, Hajjar AM: Ferreting Out the Role of Infection in

Cystic Fibrosis Lung Disease. Am J Respir Crit Care Med. 2018; 197:

1243-1244.

PubMed Abstract | Publisher Full Text

Hoffmann N, Rasmussen TB, Jensen P, et al.: Novel mouse model of

chronic Pseudomonas aeruginosa lung infection mimicking cystic

fibrosis. Infect Immun. 2005; 73: 2504-2514.

PubMed Abstract | Publisher Full Text | Free Full Text

Hogan DA, Willger SD, Dolben EL, et al.: Analysis of Lung Microbiota in Bronchoalveolar Lavage, Protected Brush and Sputum Samples from Subjects with Mild-To-Moderate Cystic Fibrosis Lung Disease. PLOS

One. 2016; 11: e0149998.

PubMed Abstract | Publisher Full Text | Free Full Text

Holloway BW: Genetic recombination in Pseudomonas aeruginosa.

J Gen Microbiol. 1955; 13: 572-581.

PubMed Abstract | Publisher Full Text

Hotterbeekx A, Kumar-Singh S, Goossens $\mathrm{H}$, et al.: In vivo and In vitro Interactions between Pseudomonas aeruginosa and Staphylococcus spp. Front Cell Infect Microbiol. 2017; 7: 106.

PubMed Abstract | Publisher Full Text | Free Full Text

Ibberson CB, Stacy A, Fleming D, et al.: Co-infecting microorganisms dramatically alter pathogen gene essentiality during polymicrobial

infection. Nat Microbiol. 2017; 2: 17079.

PubMed Abstract | Publisher Full Text | Free Full Text

Ibberson CB, Whiteley M: The social life of microbes in chronic

infection. Curr Opin Microbiol. 2020; 53: 44-50.

PubMed Abstract | Publisher Full Text | Free Full Text

Jorth P, Ehsan Z, Rezayat A, et al.: Direct Lung Sampling Indicates That

Established Pathogens Dominate Early Infections in Children with

Cystic Fibrosis. Cell Rep. 2019; 27: 1190-1204.e3.

PubMed Abstract | Publisher Full Text | Free Full Text

Josse J, Laurent F, Diot A: Staphylococcal Adhesion and Host Cell

Invasion: Fibronectin-Binding and Other Mechanisms. Front Microbiol.

2017; 8: 2433.

PubMed Abstract | Publisher Full Text | Free Full Text

Judge EP, Hughes JM, Egan JJ, et al.: Anatomy and bronchoscopy of the porcine lung. A model for translational respiratory medicine.

Am J Respir Cell Mol Biol. 2014; 51: 334-343.

PubMed Abstract | Publisher Full Text

Kirchner S, Fothergill JL, Wright EA, et al.: Use of artificial sputum medium to test antibiotic efficacy against Pseudomonas aeruginosa in conditions more relevant to the cystic fibrosis lung. J Vis Exp. 2012: e3857.

PubMed Abstract | Publisher Full Text | Free Full Text

Korgaonkar A, Trivedi U, Rumbaugh KP, et al.: Community surveillance enhances Pseudomonas aeruginosa virulence during polymicrobial infection. Proc Natl Acad Sci U S A. 2013; 110: 1059-1064. PubMed Abstract | Publisher Full Text | Free Full Text Leekha S, Terrell CL, Edson RS: General principles of antimicrobial therapy. Mayo Clin Proc. 2011; 86: 156-167.

PubMed Abstract | Publisher Full Text | Free Full Text

Leenaars CH, De Vries RB, Heming A, et al.: Animal models for cystic fibrosis: A systematic search and mapping review of the literature 
Part 1: genetic models. Lab Anim. 2020; 54: 330-340. PubMed Abstract | Publisher Full Text

Lopes SP, Azevedo NF, Pereira MO: Emergent bacteria in cystic fibrosis: in vitro biofilm formation and resilience under variable oxygen conditions. Biomed Res Int. 2014; 2014: 678301

PubMed Abstract | Publisher Full Text | Free Full Text

Lopes SP, Azevedo NF, Pereira MO: Developing a model for cystic fibrosis sociomicrobiology based on antibiotic and environmenta stress. Int J Med Microbiol. 2017; 307: 460-470.

PubMed Abstract | Publisher Full Text

Lopes SP, Ceri H, Azevedo NF, et al.: Antibiotic resistance of mixed biofilms in cystic fibrosis: impact of emerging microorganisms on treatment of infection. Int J Antimicrob Agents. 2012; 40: 260-263. PubMed Abstract | Publisher Full Text

Lubamba B, Dhooghe B, Noel S, et al.: Cystic fibrosis: insight into CFTR pathophysiology and pharmacotherapy. Clin Biochem. 2012; 45: 1132-1144.

PubMed Abstract | Publisher Full Text

Lyczak JB, Cannon CL, Pier GB: Lung infections associated with cystic fibrosis. Clin Microbiol Rev. 2002; 15: 194-222.

PubMed Abstract | Publisher Full Text | Free Full Text

Mahboubi MA, Carmody LA, Foster BK, et al.: Culture-Based and CultureIndependent Bacteriologic Analysis of Cystic Fibrosis Respiratory Specimens. J Clin Microbiol. 2016; 54: 613-619.

PubMed Abstract | Publisher Full Text | Free Full Text

Malhotra S, Hayes D, Wozniak DJ: Cystic Fibrosis and Pseudomonas aeruginosa: the Host-Microbe Interface. Clin Microbiol Rev. 2019; 32. PubMed Abstract | Publisher Full Text | Free Full Text

Markussen T, Marvig RL, Gómez-Lozano M, et al.: Environmenta heterogeneity drives within-host diversification and evolution of Pseudomonas aeruginosa. mBio. 2014; 5: e01592-e01514. PubMed Abstract | Publisher Full Text | Free Full Text

Mashburn LM, Jett AM, Akins DR, et al.: Staphylococcus aureus serves as an iron source for Pseudomonas aeruginosa during in vivo coculture. Bacteriol. 2005; 187: 554-566.

PubMed Abstract | Publisher Full Text | Free Full Text

Mastropaolo MD, Evans NP, Byrnes MK, et al.: Synergy in polymicrobial infections in a mouse model of type 2 diabetes. Infect Immun. 2005; 73 : 6055-6063.

PubMed Abstract | Publisher Full Text | Free Full Text

Moser C, Van Gennip M, Bjarnsholt T, et al.: Novel experimental

Pseudomonas aeruginosa lung infection model mimicking long-

term host-pathogen interactions in cystic fibrosis. APMIS. 2009; 117

95-107.

PubMed Abstract | Publisher Full Text | Free Full Text

Mowat E, Paterson S, Fothergill JL, et al.: Pseudomonas aeruginosa population diversity and turnover in cystic fibrosis chronic infections. Am J Respir Crit Care Med. 2011; 183: 1674-1679.

PubMed Abstract | Publisher Full Text

Munder A, Wölbeling F, Kerber-Momot T, et al.: Acute intratracheal Pseudomonas aeruginosa infection in cystic fibrosis mice is age-independent. Respir Res. 2011; 12: 148.

PubMed Abstract | Publisher Full Text | Free Full Text

O'Brien S, Fothergill JL: The role of multispecies social interactions in shaping Pseudomonas aeruginosa pathogenicity in the cystic fibrosis lung. FEMS Microbiol Lett. 2017; 364.

PubMed Abstract | Publisher Full Text | Free Full Text

O'Brien TJ, Hassan MM, Harrison F, et al.: An in vitro model for the

cultivation of polymicrobial biofilms under continuous-flow

conditions. Figshare. 2021

Publisher Full Text

O'Brien TJ, Welch M: A Continuous-Flow Model for in vitro Cultivation of Mixed Microbial Populations Associated with Cystic Fibrosis Airway Infections. Front Microbiol. 2019a; 10: 2713.

PubMed Abstract | Publisher Full Text | Free Full Text

O'Brien TJ, Welch M: Recapitulation of polymicrobial communities associated with cystic fibrosis airway infections: a perspective. Future Microbiol. 2019b; 14: 1437-1450.

PubMed Abstract | Publisher Full Text

Palmer KL, Aye LM, Whiteley M: Nutritional cues control Pseudomonas aeruginosa multicellular behavior in cystic fibrosis sputum. J Bacteriol. 2007; 189: 8079-8087.

PubMed Abstract | Publisher Full Text | Free Full Text

Palmer KL, Mashburn LM, Singh PK, et al.: Cystic fibrosis sputum supports growth and cues key aspects of Pseudomonas aeruginosa physiology. J Bacteriol. 2005; 187: 5267-5277.

PubMed Abstract | Publisher Full Text | Free Full Text

Parsek MRASPK: Bacterial Biofilms: An Emerging Link to Disease Pathogenesis. Annu Rev Microbiol. 2003; 57: 677-701.

PubMed Abstract | Publisher Full Text

Peters BM, Jabra-Rizk MA, O'May GA, et al.: Polymicrobial interactions: impact on pathogenesis and human disease. Clin Microbiol Rev. 2012;
25: 193-213.

PubMed Abstract | Publisher Full Text | Free Full Text

Quinn RA, Whiteson K, Lim YW, et al.: A Winogradsky-based culture

system shows an association between microbial fermentation and

cystic fibrosis exacerbation. ISME J. 2015; 9: 1052

PubMed Abstract | Publisher Full Text | Free Full Text

Rajan S, Saiman L: Pulmonary infections in patients with cystic fibrosis.

Semin Respir Infect. 2002; 17: 47-56.

PubMed Abstract | Publisher Full Text

Rogers CS, Abraham WM, Brogden KA, et al.: The porcine lung as a

potential model for cystic fibrosis. Am J Physiol Lung Cell Mol Physiol.

2008; 295: L240-L263.

PubMed Abstract | Publisher Full Text | Free Full Text

Rogers GB, Stressmann FA, Walker AW, et al.: Lung infections in cystic

fibrosis: deriving clinical insight from microbial complexity. Expert Rev

Mol Diagn. 2010; 10: 187-196.

PubMed Abstract | Publisher Full Text

Schick A, Kassen R: Rapid diversification of Pseudomonas aeruginosa in

cystic fibrosis lung-like conditions. Proc Natl Acad Sci U S A. 2018; 115 :

10714-10719.

PubMed Abstract | Publisher Full Text | Free Full Text

Sibley CD, Rabin H, Surette MG: Cystic fibrosis: a polymicrobial

infectious disease. Future Microbiol. 2006; 1: 53-61.

PubMed Abstract | Publisher Full Text

Sibley CD, Surette MG: The polymicrobial nature of airway infections in

cystic fibrosis: Cangene Gold Medal Lecture. Can J Microbiol. 2011; 57:

69-77.

PubMed Abstract | Publisher Full Text

Sousa AM, Monteiro R, Pereira MO: Unveiling the early events of

Pseudomonas aeruginosa adaptation in cystic fibrosis airway environment using a long-term in vitro maintenance. Int J Med

Microbiol. 2018; 308: 1053-1064.

PubMed Abstract | Publisher Full Text

Sriramulu DD, Lünsdorf $\mathrm{H}$, Lam JS, et al.: Microcolony formation: a novel biofilm model of Pseudomonas aeruginosa for the cystic fibrosis lung. J Med Microbiol. 2005; 54: 667-676.

PubMed Abstract | Publisher Full Text

Sun X, Sui H, Fisher JT, et al.: Disease phenotype of a ferret

CFTR-knockout model of cystic fibrosis. J Clin Invest. 2010; 120:

3149-3160.

PubMed Abstract | Publisher Full Text | Free Full Text

Sun $X, Y i Y$, Yan $Z$, et al.: In utero and postnatal VX-770 administration rescues multiorgan disease in a ferret model of cystic fibrosis. $\mathrm{SCi}$ Trans/ Med. 2019; 11.

PubMed Abstract | Publisher Full Text | Free Full Text

Sweeney E, Harrington NE, Harley Henriques AG, et al.: An ex vivo cystic fibrosis model recapitulates key clinical aspects of chronic Staphylococcus aureus infection. Microbiology (Reading). 2021; 167.

PubMed Abstract | Publisher Full Text

Thomas $\mathrm{P}$, Sekhar AC, Upreti R, et al.: Optimization of single plateserial dilution spotting (SP-SDS) with sample anchoring as an assured method for bacterial and yeast cfu enumeration and single colony isolation from diverse samples. Biotechnol Rep (Amst). 2015; 8:

45-55.

PubMed Abstract | Publisher Full Text | Free Full Text

Treangen TJ, Maybank RA, Enke S, et al.: Complete Genome Sequence of the Quality Control Strain Staphylococcus aureus subsp. aureus ATCC 25923. Genome Announc. 2014; 2.

PubMed Abstract | Publisher Full Text | Free Full Tex

Turner KH, Wessel AK, Palmer GC, et al.: Essential genome of Pseudomonas aeruginosa in cystic fibrosis sputum. Proc Natl Acad Sci USA. 2015; 112: 4110-4115.

PubMed Abstract | Publisher Full Text | Free Full Text

Van Heeckeren AM, Schluchter MD, Xue W, et al.: Response to acute lung infection with mucoid Pseudomonas aeruginosa in cystic fibrosis mice. Am J Respir Crit Care Med. 2006; 173: 288-296.

PubMed Abstract | Publisher Full Text | Free Full Text

Weimer KE, Armbruster CE, Juneau RA, et al.: Coinfection with Haemophilus influenzae promotes pneumococcal biofilm formation during experimental otitis media and impedes the progression of pneumococcal disease. J Infect Dis. 2010; 202 1068-1075.

PubMed Abstract | Publisher Full Text | Free Full Text

Winstanley C, O'Brien S, Brockhurst MA: Pseudomonas

aeruginosa Evolutionary Adaptation and Diversification in

Cystic Fibrosis Chronic Lung Infections. Trends Microbiol. 2016; 24

327-337

PubMed Abstract | Publisher Full Text | Free Full Text

Zhao J, Schloss PD, Kalikin LM, et al.: Decade-long bacterial community dynamics in cystic fibrosis airways. Proc Natl Acad Sci U S A. 2012; 109: 5809-5814.

PubMed Abstract | Publisher Full Text | Free Full Text 


\section{Open Peer Review}

\section{Current Peer Review Status:}

\section{Version 1}

Reviewer Report 14 September 2021

https://doi.org/10.5256/f1000research.58690.r91903

(C) 2021 Kalan L. This is an open access peer review report distributed under the terms of the Creative Commons Attribution License, which permits unrestricted use, distribution, and reproduction in any medium, provided the original work is properly cited.

\section{Lindsay R. Kalan}

Department of Medical Microbiology and Immunology, School of Medicine and Public Health, University of Wisconsin-Madison, Madison, WI, USA

The manuscript by O'brien et al. describes the development of an in vitro model for the study of polymicrobial biofilm, specifically focused on the CF lung environment. This work is timely as the importance of polymicrobial colonization, biofilm formation, and infection is increasingly recognized as important towards disease outcome. Here, the authors use artificial sputum in a continuous flow culture vessel to cultivate biofilms. They examined biofilm formation using two different substrates, agar or ex vivo porcine lung tissues. This allows the user to evaluate both biofilm growth on the substrate and measure planktonic cell populations in the surrounding media.

The manuscript is well written, and the photographs of the apparatus are helpful to the reader who wishes to set this up in their own laboratory. The protocol provided is detailed and thorough although the production of ASM media seems cumbersome with some steps requiring first hand know-how that may introduce variability. For example, the filtration step is stated to take up to 2-3 days with the membrane being rinsed periodically, it is unclear how this might introduce contamination or impact the final media composition.

I have no major comments, minor comments follow:

The protocol states that each species in inoculated at an OD600 of 0.05 . This could vary in the final cfu/mL depending on the species, especially fungi. It may be more informative to state the desired final inoculum in $\mathrm{cfu} / \mathrm{mL}$ or total CFUs.

The substrates are washed three times after incubation and before final quantification of biofilm. I wonder if these washes are ever quantified. This may be important to determine if the wash step disrupts significant amounts of biofilm for organisms that are loosely adherent or reaching maturity and may dislodge due to sheer pressure. This could possibly be the case with S. aureus.

Figure 4 is not overly informative showing CFUs of overnight cultures. However, if the main 
point is that the selective media does not impact growth and quantification, the legend should state the selective media used for each species including any antibiotics/antifungals in the media.

The authors state in the discussion that the model is amenable to longitudinal studies of polymicrobial biofilm for extended periods of time. However, this study only went out to 96 hrs. It is not clear how long or how stable these communities may be over longer periods. If the model allows for study over several days and even weeks this is very powerful. This information must be determined for each community, however the authors could address their experience with the three-member model community reported in this manuscript in the discussion.

Are a suitable application and appropriate end-users identified?

Yes

If applicable, is the statistical analysis and its interpretation appropriate?

Yes

Are the 3Rs implications of the work described accurately?

Yes

Is the rationale for developing the new method (or application) clearly explained?

Yes

Is the description of the method technically sound?

Yes

Are sufficient details provided to allow replication of the method development and its use by others?

Yes

If any results are presented, are all the source data underlying the results available to ensure full reproducibility?

Yes

Are the conclusions about the method and its performance adequately supported by the findings presented in the article?

Yes

Competing Interests: No competing interests were disclosed.

Reviewer Expertise: Polymicrobial interactions, biofilm, chronic infection

I confirm that I have read this submission and believe that I have an appropriate level of expertise to confirm that it is of an acceptable scientific standard. 
Reviewer Report 20 August 2021

https://doi.org/10.5256/f1000research.58690.r91897

(C) 2021 Neill D. This is an open access peer review report distributed under the terms of the Creative Commons Attribution License, which permits unrestricted use, distribution, and reproduction in any medium, provided the original work is properly cited.

\section{Daniel R. Neill}

Institute of Infection, Veterinary and Ecological Science, University of Liverpool, Liverpool, UK

O'Brien and colleagues describe a novel model system for the study of polymicrobial biofilms, under conditions designed to reflect those of the cystic fibrosis airways. The authors have built on their previous study that described a continuous-flow model for cultivation of mixed microbial populations. The neat addition, described here, is a metal gauze cage that can be loaded with substrata on which microbial biofilm communities can form. In the examples presented, cubes of agar or ex vivo porcine bronchioles are used. Culture in artificial sputum media provides environmental conditions reflective of the CF airways.

This is a very well presented manuscript, with a carefully considered introduction and sufficient methodological detail to enable other users to establish the model in their own labs. The discussion describes further applications for the model that all appear realistic. I agree with the authors' assertion that this model has potential to reduce or replace animal use for study of polymicrobial biofilms in CF and related conditions, albeit dependent upon the experimental question under consideration.

This is primarily a methods paper, so the experimental findings are understandably limited. Nonetheless, I thought the observation of steady planktonic microbial density but fluctuating biofilm densities/composition was an interesting one. There is clear potential for further informative science to be undertaken using this model system.

I have no major criticisms of the work. I thought the study had been well planned, carefully executed and nicely presented. I have no doubt that others with interests in polymicrobial infections of the CF lung will find the model useful, and I can see it being adapted for study of infection in other chronic lung conditions, as the authors suggest.

Below, I include a few minor comments that the authors may wish to consider:

The introduction mentions the limits of in vitro systems as being the lack of host cells and an immune system. I would add that most fail to capture the spatial heterogeneity of the respiratory tract. Chemical, nutritional, and microbial conditions differ between anatomical sites within the upper and lower airways and between different foci of infection within lungs. These differences may influence the dynamics of infection, the balance of competing pathogens in the airway space and may also contribute to treatment failure.

The introduction states that "it should be noted that impaired immune clearance of microbes is an inherent feature of $C F$, which somewhat mitigates the lack of a functional immune system in in vitro models." I take the authors point on this, but it is an oversimplification. Inefficient 
immune clearance is not the same as having no immune response at all. There is still potential for interactions between soluble and cellular immune defences and bacterial pathogens to influence microbial phenotypes. The authors do partially address this point in their discussion, but I think this section of the intro is slightly misleading.

For the presentation of results, I wondered whether $\mathrm{CFU} / \mathrm{cm}^{2}$ of substratum might be more informative than per $\mathrm{ml}$ ? If this is too challenging to quantify, then per gram of agar/EVPL would at least account for differences in preparation between individual cubes.

In the section on the microbial densities within biofilm, I was interested in whether there was much difference between biological replicates (i.e. between cubes). Does PA outcompete SA every time or does it depend on which gets a foothold first? Do you ever find cubes that are completely dominated by a single pathogen? This information is available within the source data file, but would be easier to digest in a graph presenting the biological replicates for each species side by side.

The authors postulated explanations for the relative success of PA vs SA on EVPL are intriguing, but this section should acknowledge that only one strain of each species has been tested. PAO1 is fast growing compared to many PA isolates from CF and this may contribute to the observed outcomes.

Although clearly beyond the scope of this manuscript, I was interested as to how the authors think the model may need to be adapted to better reflect the environmental conditions of the CF lung now that patients are moving over to CFTR modulator therapies?

Are a suitable application and appropriate end-users identified?

Yes

If applicable, is the statistical analysis and its interpretation appropriate? Yes

Are the 3Rs implications of the work described accurately? Yes

Is the rationale for developing the new method (or application) clearly explained? Yes

Is the description of the method technically sound? Yes

Are sufficient details provided to allow replication of the method development and its use by others?

Yes

If any results are presented, are all the source data underlying the results available to ensure full reproducibility?

Yes 
Are the conclusions about the method and its performance adequately supported by the findings presented in the article?

Yes

Competing Interests: I am a co-investigator on a multi-centre research grant on which Dr Harrison is also a named co-investigator and we are contributing work to separate work packages.

Reviewer Expertise: Referee suggested by the NC3Rs for their scientific expertise and experience in assessing 3Rs impact. My research is focussed on bacterial infections of the respiratory tract, including those of the CF lung. I also have interests in development of in vitro and in vivo infection models that reflect respiratory tract environments.

I confirm that I have read this submission and believe that I have an appropriate level of expertise to confirm that it is of an acceptable scientific standard.

The benefits of publishing with F1000Research:

- Your article is published within days, with no editorial bias

- You can publish traditional articles, null/negative results, case reports, data notes and more

- The peer review process is transparent and collaborative

- Your article is indexed in PubMed after passing peer review

- Dedicated customer support at every stage

For pre-submission enquiries, contact research@f1000.com 